\title{
Graphene-Based Photo-Fenton Catalysts for Pollutant Control
}

\author{
Yan Bao ${ }^{1}$ Q Qingyun Yan ${ }^{1} \cdot$ Jiahui Ji ${ }^{1} \cdot$ Bocheng Qiu ${ }^{2} \cdot$ Jinlong Zhang ${ }^{1} \cdot$ Mingyang Xing $^{1}$
}

Received: 16 October 2020 / Revised: 23 October 2020 / Accepted: 2 November 2020 / Published online: 4 January 2021

(c) The Author(s) 2020

\begin{abstract}
Water pollution is a global environmental issue with multi-dimensional influences on human life. Some strategies, such as photo-Fenton reaction, have been employed to remove recalcitrant pollutants. Two-dimensional (2D) graphene and its threedimensional (3D) configurations have attracted considerable attention as emerging carbon-based catalysts in photo-Fenton fields owing to their alluring properties in electron transfer, reactant adsorption, and light response. This review summarizes the recent developments in 2D and 3D graphene-based catalysts for photo-Fenton reactions. Their structures, characteristics, activity, and mechanisms are discussed. The conclusions and outlooks are proposed for the profound understanding of challenges and future directions.
\end{abstract}

Keywords Photo-Fenton $\cdot$ Graphene $\cdot$ Pollutant control $\cdot$ Aerogel $\cdot$ Hydrogel

\section{Introduction}

With continuous developments of human societies and industries, water pollution is becoming increasingly serious and riveting attention among researchers. Although a small fraction of pollutants is present in aquatic environments, most of them bio-accumulate and resist traditional physical removal methods [1]. Consequently, innovative strategies, such as advanced oxidation processes (AOPs), have been introduced; the Fenton reaction, which was discovered in 1894, is one of the most studied strategies [2-10]. The main reactions stated below [Eqs. (1), (2)] reveal the major oxidation mechanism, where ferrous ions $\left(\mathrm{Fe}^{2+}\right)$ continuously react with hydrogen peroxide $\left(\mathrm{H}_{2} \mathrm{O}_{2}\right)$ to produce hydroxyl radicals $(\cdot \mathrm{OH})$ with strong oxidizing ability, which plays a

Bocheng Qiu

bochengqiu@njau.edu.cn

Mingyang Xing

mingyangxing@ecust.edu.cn

1 Key Laboratory for Advanced Materials and Joint International Research Laboratory of Precision Chemistry and Molecular Engineering, Feringa Nobel Prize Scientist Joint Research Center, School of Chemistry and Molecular Engineering, East China University of Science and Technology, Shanghai 200237, China

2 Jiangsu Key Laboratory of Pesticide Sciences, Department of Chemistry, College of Sciences, Nanjing Agricultural University, Nanjing 210095, China vital role in the subsequent degradation of pollutants. The concurrent reduction of ferric ions $\left(\mathrm{Fe}^{3+}\right)$ to $\mathrm{Fe}^{2+}$ realizes the circulation of iron ions. However, Eq. (2) is the ratedetermining step, whose rate is approximately $1 / 6000$ that of Eq. (1), which greatly abates the effectiveness of $\mathrm{Fe}^{3+} /$ $\mathrm{Fe}^{2+}$ circulation [11]. The invalidation of $\mathrm{Fe}^{3+} / \mathrm{Fe}^{2+}$ circulation induces not only the insufficient utilization efficiency of $\mathrm{H}_{2} \mathrm{O}_{2}$ but also the aggregation of $\mathrm{Fe}^{3+}$. It precipitates to form ferric hydroxide $\left(\mathrm{Fe}(\mathrm{OH})_{3}\right)$, namely iron sludge, when $\mathrm{pH}$ is above 3 , leading to thorny secondary pollution [12]. Traditional Fenton reactions possess four major drawbacks: (1) low utilization efficiency of $\mathrm{H}_{2} \mathrm{O}_{2}$, (2) narrow $\mathrm{pH}$ range, (3) excess iron ion loss and secondary pollution of iron sludge, and (4) difficulties in recycling powder catalysts [13-16].

$\mathrm{Fe}^{2+}+\mathrm{H}_{2} \mathrm{O}_{2}+\mathrm{H}^{+} \rightarrow \mathrm{Fe}^{3+}+\cdot \mathrm{OH}+\mathrm{H}_{2} \mathrm{O}$

$\mathrm{Fe}^{3+}+\mathrm{H}_{2} \mathrm{O}_{2} \rightarrow \mathrm{Fe}^{2+}+\mathrm{HO}_{2} \cdot+\mathrm{H}^{+}$

As a branch of Fenton reactions, the photo-Fenton reaction improves the utilization efficiency of $\mathrm{H}_{2} \mathrm{O}_{2}$ after the introduction of ultraviolet (UV) or visible light because of the photo-induced reduction of $\mathrm{Fe}^{3+}$ to $\mathrm{Fe}^{2+}$ [Eq. (3)] and the production of $\cdot \mathrm{OH}$ [Eq. (4)] [11]. In traditional photoFenton reactions, ferrous compounds, such as ferrous sulfate $\left(\mathrm{FeSO}_{4}\right)$, are added directly into aqueous catalytic systems to react with $\mathrm{H}_{2} \mathrm{O}_{2}$ in ionic state [17]. Such type of homogeneous reaction exacerbates the formation of iron sludge, resulting in blocked iron recycling and secondary 
pollution [18]. Iron-based catalysts may contribute to interface reactions between iron ions and $\mathrm{H}_{2} \mathrm{O}_{2}$, suppressing the formation of iron sludge and waste of iron sources [19]. Various methods to introduce iron-based catalysts have been investigated to ameliorate the application range of $\mathrm{pH}$, formation of iron sludge, and catalyst recycling in photo-Fenton reactions [20, 21].

$[\mathrm{Fe}(\mathrm{OH})]^{2+}+h \nu \rightarrow \mathrm{Fe}^{2+}+\cdot \mathrm{OH}$

$\mathrm{H}_{2} \mathrm{O}_{2}+h v \rightarrow 2 \cdot \mathrm{OH}$

In photo-Fenton reactions, a myriad of catalysts display their outstanding potential in degrading recalcitrant pollutants. In recent years, graphene-based materials have become promising candidates owing to their unique merits of theoretical specific surface, electron mobility, wide light response, and mechanical strength [22, 23]. Numerous reports have proved the overwhelming benefits of graphene in various AOPs, including photo-Fenton reactions [24]. Early in 2011, Fu and Wang [25] loaded $\mathrm{ZnFe}_{2} \mathrm{O}_{4}$ on graphene and applied the $\mathrm{ZnFe}_{2} \mathrm{O}_{4}$-graphene hybrid catalyst for the photo-Fenton reaction in degrading methylene blue (MB). The salient improvement over pristine $\mathrm{ZnFe}_{2} \mathrm{O}_{4}$ is ascribed to the enhanced light absorbance of graphene and inherent $\pi$-conjunction in graphene, which is conducive for the separation of photo-generated electrons and holes, thus extending the lifetime of photo-generated electrons. Moreover, the introduction of graphene in the photo-Fenton reaction can quickly transfer the electrons to $\mathrm{Fe}^{3+}$, accelerating its reduction to $\mathrm{Fe}^{2+}$ and enabling the $\mathrm{Fe}^{3+} / \mathrm{Fe}^{2+}$ circulation in the photo-Fenton reaction. In addition, the large specific surface endows graphenebased catalysts with the preeminent adsorption of pollutants and retards the agglomeration of catalyst nanoparticles [26-28]. Figure 1 illustrates the general photo-Fenton scheme of graphene-based materials.

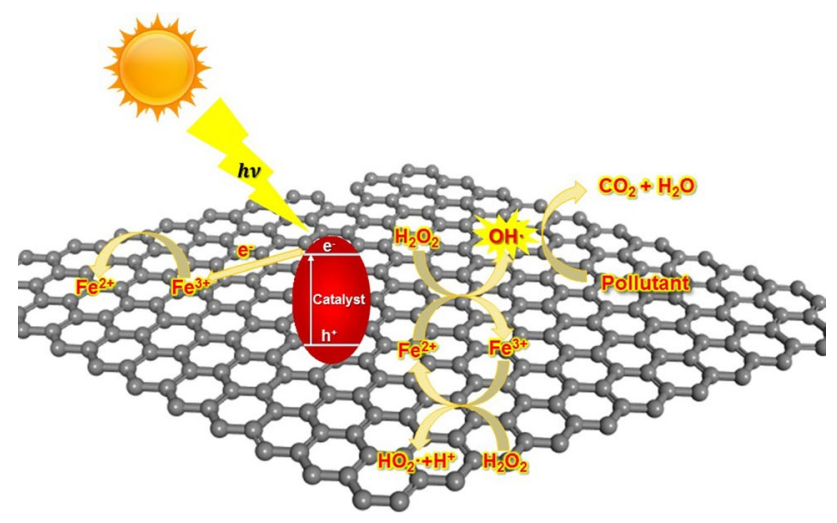

Fig. 1 General photo-Fenton scheme of graphene-based materials
Given the peculiar properties and alluring prospects of graphene in photo-Fenton reactions, this review summarized the recent advances in graphene-based photo-Fenton catalysts and categorized them into 2D and 3D graphenebased photo-Fenton systems, whose structures, characteristics, activity, and mechanisms were discussed in detail. Moreover, attempts to overcome the four aforementioned drawbacks that hampered the practical application of photoFenton reactions were presented. On the basis of the above analysis, a perspective on the direction and emphasis in this field was provided to understand the possible path of photoFenton reactions in practical industrial wastewater treatment.

\section{Two-Dimensional Graphene-Based Photo-Fenton Systems}

Graphene oxide (GO) obtained by the exfoliation and oxidation of graphite possesses oxygen-containing functional groups on the surface $[29,30]$. These functional groups allow GO to chemically bond with various active materials and form highly stable 2D graphene-based photo-Fenton systems. Consequently, the high stability, great dispersity, and rapid reaction of $2 \mathrm{D}$ graphene-based photo-Fenton systems triggered a myriad of studies. Iron-based catalysts have been extensively applied in recent research to restrain the formation of iron sludge. As a result, recently developed 2D graphene-based photo-Fenton systems were divided into 2D graphene/iron oxides, 2D graphene/spinel ferrites, and 2D graphene/iron-based metal organic frameworks, whose characteristics, advantages, and mechanisms were introduced specifically.

\section{Two-Dimensional Graphene/Iron Oxides}

Multifarious iron oxides with nanostructures have attracted considerable attention because of their natural abundance, environmental friendliness, and efficient production of iron complex and $\cdot \mathrm{OH}$ irradiated by UV light [31]. So far, ferric oxide $\left(\mathrm{Fe}_{2} \mathrm{O}_{3}\right)[31,32]$, ferriferous oxide $\left(\mathrm{Fe}_{3} \mathrm{O}_{4}\right)$ [33, 34], and iron oxyhydroxide (FeOOH) [35] display peculiar properties and compelling catalytic ability with the aid of graphene in photo-Fenton reactions.

As an earth-abundant n-type semiconductor, $\alpha-\mathrm{Fe}_{2} \mathrm{O}_{3}$ stands out as the most discussed crystalline polymorph of $\mathrm{Fe}_{2} \mathrm{O}_{3}$ because of its low cost, heat endurance, and chemical stability. With a relatively narrow band gap of $1.90-2.20 \mathrm{eV}$, $\alpha-\mathrm{Fe}_{2} \mathrm{O}_{3}$ can absorb approximately $43 \%$ solar light $[32,36]$ and releases few iron ions as a heterogeneous Fenton catalyst [31]. Nevertheless, the inherent high recombination rate of photo-generated electrons and holes and inefficient conversion efficiency of $\mathrm{Fe}^{2+}$ and $\mathrm{Fe}^{3+}$ in $\alpha-\mathrm{Fe}_{2} \mathrm{O}_{3}$ hamper the overall catalysis in photo-Fenton reactions [32]. With 
its fascinating electron transport property and large specific surface area, graphene is regarded as a promising support to overcome the demerits of $\alpha-\mathrm{Fe}_{2} \mathrm{O}_{3}$. Guo et al. [37] first synthesized a $\mathrm{GO}-\mathrm{Fe}_{2} \mathrm{O}_{3}$ composite through a simple impregnation method and used it as the photo-Fenton catalyst in degrading Rhodamine B (RhB). As shown in Fig. 2a, Fourier-transform infrared (FT-IR) spectroscopy was employed to analyze the oxygen-containing functional groups before and after impregnation to identify the chemical structures of GO and GO- $\mathrm{Fe}_{2} \mathrm{O}_{3}$. The peaks at 1719, 1621, 1417, 1223, and $1053 \mathrm{~cm}^{-1}$, which were ascribed to $\mathrm{C}=\mathrm{O}$, aromatic $\mathrm{C}=\mathrm{C}$, carboxyl $\mathrm{C}-\mathrm{O}$, epoxy $\mathrm{C}-\mathrm{O}$, and alkoxy $\mathrm{C}-\mathrm{O}$, respectively, appeared in $\mathrm{GO}$ and $\mathrm{GO}-\mathrm{Fe}_{2} \mathrm{O}_{3}$ but were slightly different in their positions and sharpness, suggesting change in coordination environment of these groups. In specific, the peak at $1719 \mathrm{~cm}^{-1}$ was weaker in $\mathrm{GO}-\mathrm{Fe}_{2} \mathrm{O}_{3}$ than that in $\mathrm{GO}$ because of the formation of $-\mathrm{COO}^{-}$after loading $\mathrm{Fe}_{2} \mathrm{O}_{3}$. In addition, the extra peak at $535 \mathrm{~cm}^{-1}$ ascribed to $\mathrm{Fe}-\mathrm{O}$ in $\mathrm{Fe}_{2} \mathrm{O}_{3}$ elucidated the connection between $\mathrm{Fe}_{2} \mathrm{O}_{3}$ and $-\mathrm{COO}^{-}$on the edge of $\mathrm{GO}$, corroborating that $\mathrm{Fe}_{2} \mathrm{O}_{3}$ could form bonds with oxygen-containing functional groups on the GO surface and be firmly fixed on GO. Degradation tests revealed that $\mathrm{GO}-\mathrm{Fe}_{2} \mathrm{O}_{3}$ greatly accelerated photo-Fenton reactions (Fig. 2b), where 99\% $\mathrm{RhB}$ was degraded in 40 min. Removal of $60 \% \mathrm{RhB}$ in 80 min under dark conditions also demonstrated the preeminent adsorption ability of GO- $\mathrm{Fe}_{2} \mathrm{O}_{3}$. Moreover, $90.9 \% \mathrm{RhB}$ was eliminated in $80 \mathrm{~min}$ when $\mathrm{pH}$ was up to 10.09 , suggesting that the electronegativity and the oxygen-containing functional groups on the GO surface extended the $\mathrm{pH}$ application range to some extent.
Liu et al. [31] subsequently investigated the mechanism of degrading different organic pollutants in the $\alpha-\mathrm{Fe}_{2} \mathrm{O}_{3} @ \mathrm{GO}$ photo-Fenton system. Ultraviolet and visible diffuse reflectance spectroscopy (UV-Vis DRS) (Fig. 2c) revealed that $\alpha-\mathrm{Fe}_{2} \mathrm{O}_{3} @ \mathrm{GO}$ showed an enhanced light absorption and slight redshift than $\alpha-\mathrm{Fe}_{2} \mathrm{O}_{3}$, indicating that the former has greater photo-Fenton efficiency than the latter. Such slight redshift might be credited to the formation of $\mathrm{Fe}-\mathrm{O}-\mathrm{C}$ bond between $\alpha-\mathrm{Fe}_{2} \mathrm{O}_{3}$ and GO. The degradation rates of $\mathrm{MB}$ at $\mathrm{pH} 3-12$ reached $99 \%$ in $80 \mathrm{~min}$, suggesting that $\pi-\pi$ stacking and electronegativity of the GO surface allowed $\alpha-\mathrm{Fe}_{2} \mathrm{O}_{3} @ \mathrm{GO}$ to adsorb MB in large quantities. To validate this theory, the authors conducted degradation and adsorption experiments on different organic pollutants (Fig. 2d). Results showed that the degradation and adsorption of cationic compounds ( $\mathrm{MB}$ and $\mathrm{RhB}$ ) were conspicuously quicker than those of anionic compounds (Orange II and Orange G) and neutral compounds (phenol, 2-nitrophenol, and endocrine disrupting compound $17 \beta$-estradiol), proving the aforementioned speculation. Moreover, the degradation rate of MB remained $99 \%$ after 10 cycles, and no detectable iron leaching was identified by inductively coupled plasma (ICP)-optical emission spectroscopy, suggesting the outstanding catalytic stability and inhibition of iron sludge formation in this $\alpha-\mathrm{Fe}_{2} \mathrm{O}_{3} @ \mathrm{GO}$ photo-Fenton system.

Bio-friendly $\mathrm{Fe}_{3} \mathrm{O}_{4}$ nanoparticles are promising photocatalysts because of their unique magnetic, electronic, and catalytic properties. The coexistence of $\mathrm{Fe}^{2+}$ and $\mathrm{Fe}^{3+}$ in the octahedral structure endows $\mathrm{Fe}_{3} \mathrm{O}_{4}$ with the enhanced ability of iron ion cycle [33]. The inherent magnetic property allows
Fig. 2 a FT-IR spectra of GO and $\mathrm{GO}-\mathrm{Fe}_{2} \mathrm{O}_{3}$; b discoloration of $\mathrm{RhB}$ under different conditions: (a) $\mathrm{RhB} / \mathrm{H}_{2} \mathrm{O}_{2}$ /Vis; (b) $\mathrm{RhB} / \mathrm{H}_{2} \mathrm{O}_{2}$, in the dark; (c) $\mathrm{RhB} / \mathrm{GO}-\mathrm{Fe}_{2} \mathrm{O}_{3}$, in the dark; (d) $\mathrm{RhB} / \mathrm{GO}-\mathrm{Fe}_{2} \mathrm{O}_{3} / \mathrm{Vis}$; (e) RhB/ $\mathrm{GO}-\mathrm{Fe}_{2} \mathrm{O}_{3} / \mathrm{H}_{2} \mathrm{O}_{2}$, in the dark; (f) $\mathrm{RhB} / \mathrm{GO}-\mathrm{Fe}_{2} \mathrm{O}_{3} / \mathrm{H}_{2} \mathrm{O}_{2} / \mathrm{Vis}$; and $(\mathrm{g}) \mathrm{RhB} / \mathrm{Fe}^{3+} / \mathrm{H}_{2} \mathrm{O}_{2} / \mathrm{Vis}$. Reproduced with permission from Ref. [37]. Copyright 2013 Elsevier Ltd. c UV-Vis diffuses reflectance spectra of $\alpha-\mathrm{Fe}_{2} \mathrm{O}_{3}$ and $\alpha-\mathrm{Fe}_{2} \mathrm{O}_{3} @ \mathrm{GO} ; \mathbf{d}$ degradation of various organics in the $\alpha-\mathrm{Fe}_{2} \mathrm{O}_{3} @ \mathrm{GO}+\mathrm{H}_{2} \mathrm{O}_{2}+$ UV system. Reproduced with permission from Ref. [31]. Copyright 2017 Elsevier B.V.
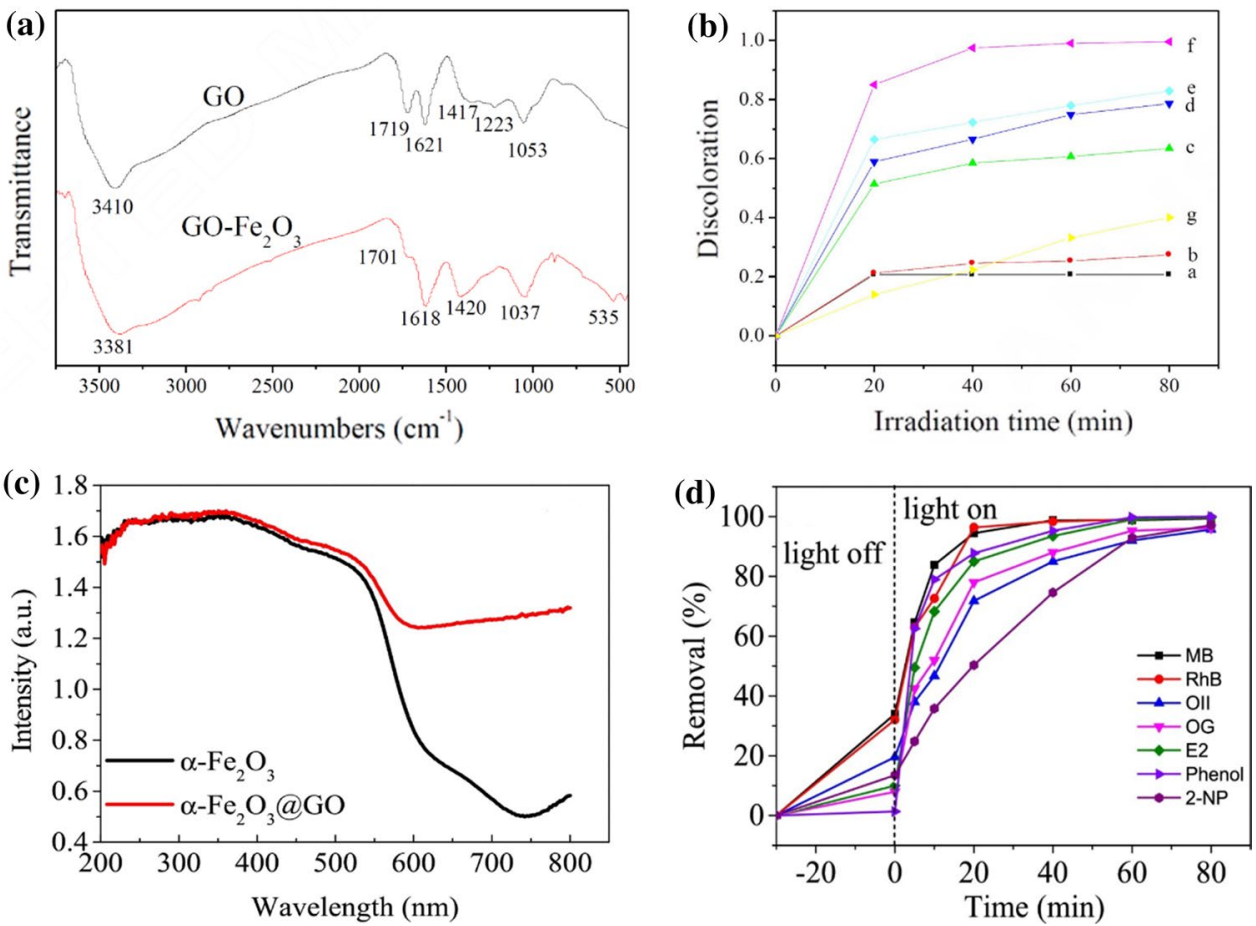
$\mathrm{Fe}_{3} \mathrm{O}_{4}$ composite catalysts to be separated from wastewater with minor loss in the presence of an external magnetic field, which is a possible solution to the difficulty in recycling photo-Fenton catalysts. However, $\mathrm{Fe}_{3} \mathrm{O}_{4}$ nanoparticles agglomerate and form large particles, which reduces the specific surface area and solubility, thereby suppressing catalytic activity [27]. To this end, the researchers loaded $\mathrm{Fe}_{3} \mathrm{O}_{4}$ nanoparticles on the GO surface and employed the composite catalysts in photo-Fenton reactions. Qiu et al. [20] reported a feasible Stöber-like method using Fe(III) acetylacetonate as the precursor to synthesize ultra-dispersed $\mathrm{Fe}_{3} \mathrm{O}_{4}$ nanoparticles on the surface of reduced graphene oxide (rGO). This method could be applied in large-scale synthesis without the need for reducing agents and organic surfactants. High-resolution transmission electron micrographs (Fig. 3a, b) showed that amorphous $\mathrm{Fe}_{3} \mathrm{O}_{4}$ nanoparticles $(3-4 \mathrm{~nm})$ dispersed uniformly on the surface of almost two layers of GO sheets. No naked GO sheets or scattered $\mathrm{Fe}_{3} \mathrm{O}_{4}$ nanoparticles were observed. This result manifested that the authors successfully synthesized $\mathrm{Fe}_{3} \mathrm{O}_{4}$ nanoparticles highly dispersed on the GO surface through the Stöber-like method. The obtained $\mathrm{Fe}_{3} \mathrm{O}_{4} / \mathrm{GO}$ catalyst showed a compelling specific surface area $\left(199.8 \mathrm{~m}^{2} / \mathrm{g}\right)$. The superior adsorption capability stemming from the large specific surface area greatly contributed to the degradation of $98 \%$ methyl orange (MO) in $30 \mathrm{~min}$ in photo-Fenton reactions. By virtue of the particular magnetic property of $\mathrm{Fe}_{3} \mathrm{O}_{4}$ nanoparticles, the catalysts were recovered rapidly without loss and difficulties (Fig. 3c). As displayed in Fig. 3d, the $\mathrm{Fe}_{3} \mathrm{O}_{4} / \mathrm{GO}$ catalyst was compared with commercial $\mathrm{Fe}_{3} \mathrm{O}_{4}$ powders in the photo-Fenton degradation of MO. The degradation rate remained $90 \%$ after four cycles with the $\mathrm{Fe}_{3} \mathrm{O}_{4} /$
$\mathrm{GO}$ catalyst, whereas commercial $\mathrm{Fe}_{3} \mathrm{O}_{4}$ powders lost the catalytic activity notably in each cycle. It was ascribed to the generation of iron sludge, which covered the surface of $\mathrm{Fe}_{3} \mathrm{O}_{4}$ and induced inefficient $\mathrm{Fe}^{3+} / \mathrm{Fe}^{2+}$ circulation. In this $\mathrm{Fe}_{3} \mathrm{O}_{4} / \mathrm{GO}$ photo-Fenton system, the photo-induced electrons generated from dyes and $\mathrm{Fe}_{3} \mathrm{O}_{4}$ migrated to $\mathrm{GO}$ sheets for the superior conductivity, so that $\mathrm{Fe}^{3+}$ could capture electrons and be reduced to $\mathrm{Fe}^{2+}$, thereby continuing to react with $\mathrm{H}_{2} \mathrm{O}_{2}$ to produce $\cdot \mathrm{OH}$. The proposed mechanism was concordant with the fact that no change in the $\mathrm{Fe}_{3} \mathrm{O}_{4} / \mathrm{GO}$ catalyst was observed before and after the photo-Fenton reactions from the transmission electron microscopy (TEM) and field-emission scanning electron microscopy (FESEM) images.

$\beta$-FeOOH has also attracted attention because of its natural abundance as a biocompatible catalyst. With the narrow band gap of $2.12 \mathrm{eV}, \beta-\mathrm{FeOOH}$ can effectively absorb visible light. However, $\beta$-FeOOH minerals usually exist in the form of very small particles, which tend to agglomerate, thus causing inactivation. In addition, the inherent poor electron-hole separation ability results in the short lifetime of photo-generated electrons and poor catalytic ability in photo-Fenton reactions $[35,38]$. To overcome these defects, Su et al. [35] prepared a $\beta-\mathrm{FeOOH} @$ GO nanocomposite through moderate hydrolysis for MB degradation. UV-Vis DRS (Fig. 4a) revealed that $\beta$-FeOOH@GO was more capable than $\beta-\mathrm{FeOOH}$ in absorbing UV and visible light owing to the interface interaction between $\beta-\mathrm{FeOOH}$ and GO sheets. In the photoluminescence (PL) spectra (Fig. 4b), the peak of $\beta-\mathrm{FeOOH} @ \mathrm{GO}$ was lower than that of $\beta$-FeOOH, suggesting stronger inhibitory effect on the recombination of photo-generated electrons and holes and
Fig. 3 a, b HRTEM of the amorphous $\mathrm{Fe}_{3} \mathrm{O}_{4} / \mathrm{GO}$ composites; c magnetic separation property of the $\mathrm{Fe}_{3} \mathrm{O}_{4} / \mathrm{RGO}$ photocatalyst; $\mathbf{d}$ cycle test $\left(\mathrm{i}_{1}-\mathrm{i}_{4}: \mathrm{Fe}_{3} \mathrm{O}_{4} / \mathrm{RGO} ; \mathrm{ii}_{1}-\mathrm{ii}_{4}\right.$ : commercial $\mathrm{Fe}_{3} \mathrm{O}_{4}$ powders; $\mathrm{iii}_{1}: \mathrm{Fe}_{3} \mathrm{O}_{4} / \mathrm{RGO}$ in the dark) for the solar-driven degradation of MO under simulated solar light irradiation. Reproduced with permission from Ref. [20]. Copyright 2015 Elsevier B.V.

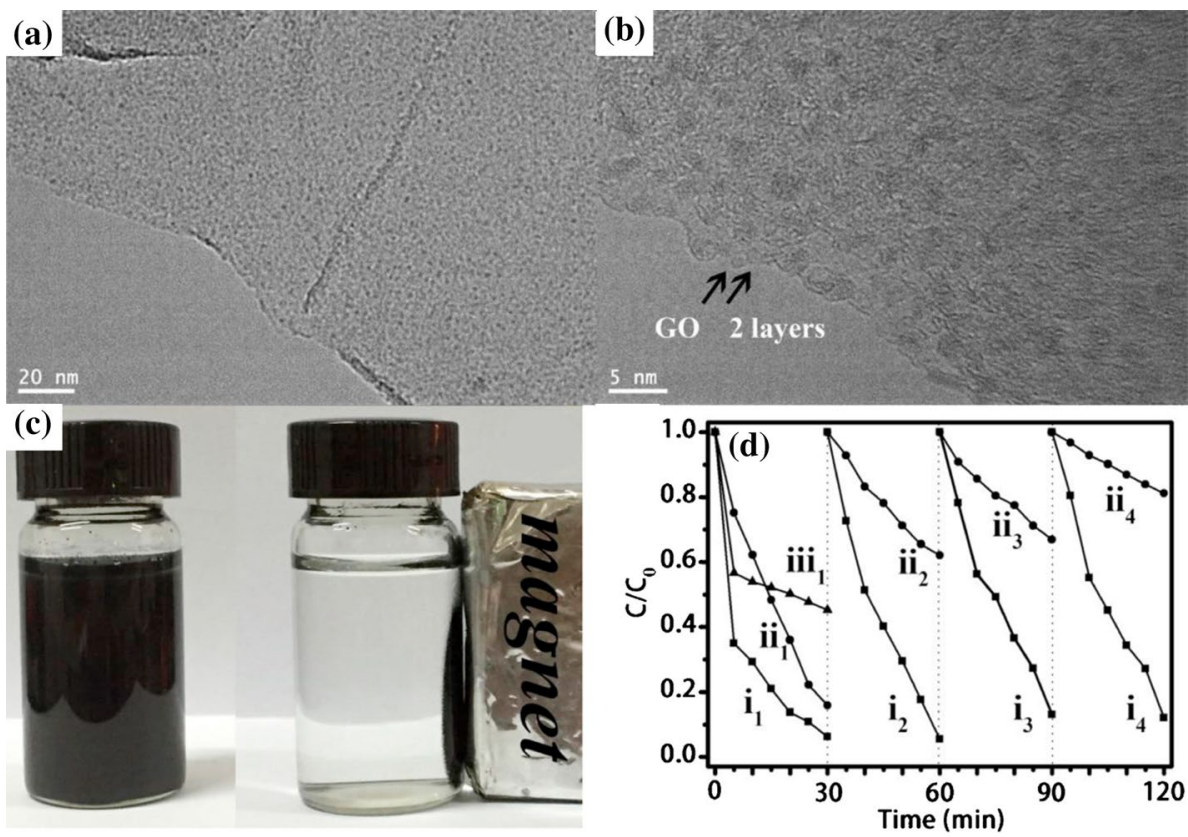


Fig. 4 a UV-Vis DRS and b PL spectra of $\beta-\mathrm{FeOOH}$ and $\beta$-FeOOH@GO; c effect of $\mathrm{pH}$ on the MB decolorization and d durability of the catalyst after six recycles in the $\beta-\mathrm{FeOOH} @$ $\mathrm{GO}+\mathrm{H}_{2} \mathrm{O}_{2}+\mathrm{UV}$ system Reproduced with permission from Ref. [35]. Copyright 2018 Elsevier Ltd.
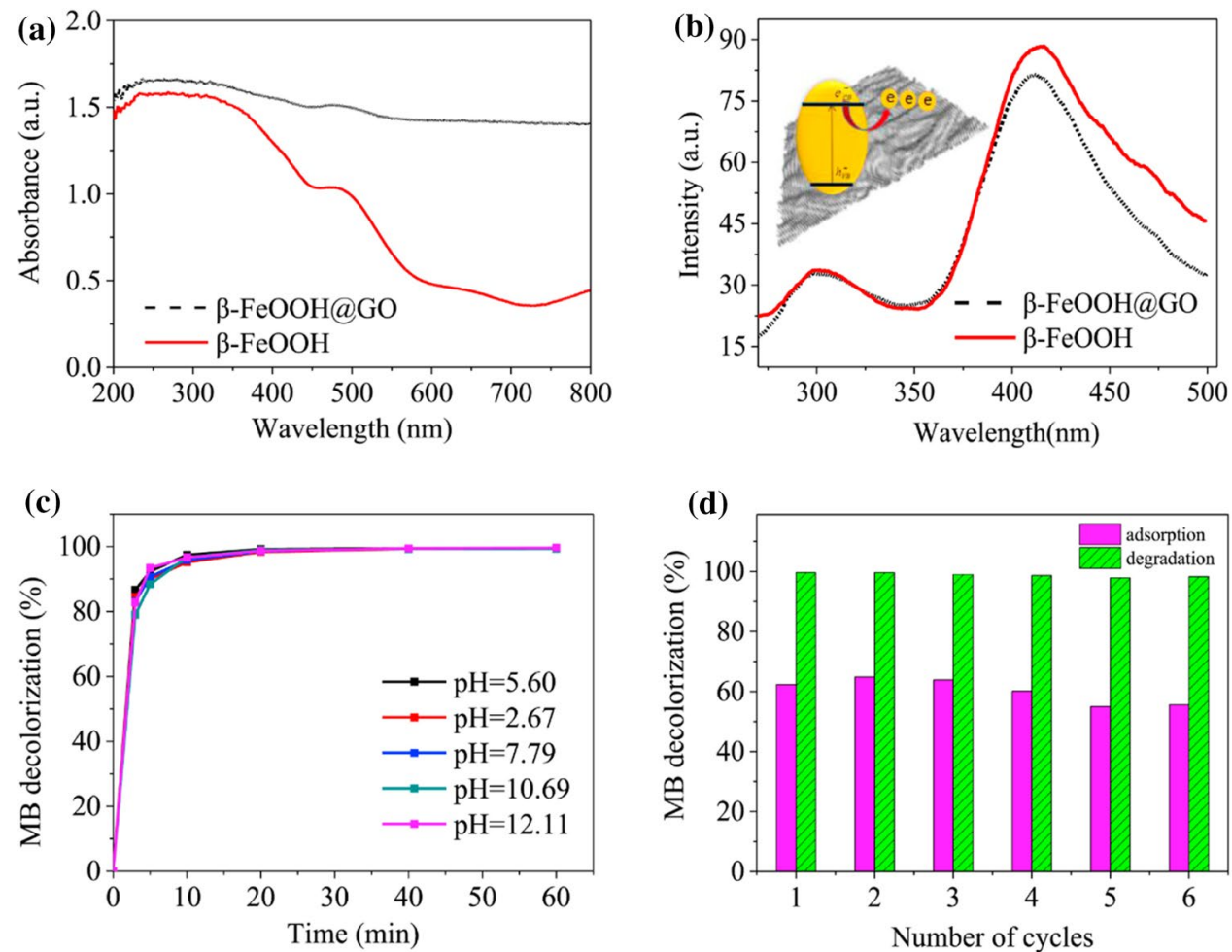

longer lifetime of photo-generated electrons. As a result, the degradation rate of $\mathrm{MB}$ with $\beta-\mathrm{FeOOH} @ \mathrm{GO}$ reached $99.7 \%$ in $60 \mathrm{~min}$, and the calculated pseudo-first-order rate constant was $0.6322 \mathrm{~min}^{-1}$, which was much higher than that of $\beta$-FeOOH $\left(0.2148 \mathrm{~min}^{-1}\right)$. Moreover, the $\mathrm{pH}$ application range and catalytic stability of $\beta-\mathrm{FeOOH} @ \mathrm{GO}$ were satisfactory. As shown in Fig. 4c, the degradation of MB with the addition of $\beta-\mathrm{FeOOH} @ \mathrm{GO}$ remained in a high speed at $\mathrm{pH} 2.67-12.11$. This result can be ascribed to the fact that the point of zero charge of $\beta$-FeOOH@ GO was 2.25 and the negatively charged surface at higher $\mathrm{pH}$ value $(\mathrm{pH}>2.25)$ augmented the adsorption of cationic MB. As illustrated in Fig. $4 d$, the degradation and adsorption rates of different cycles showed no significant differences. The maximum concentration of dissolved iron was $0.277 \mathrm{mg} / \mathrm{L}$, accounting for only $0.4 \%$ of the loaded $\beta-\mathrm{FeOOH}$. These results indicate that the $\beta-\mathrm{FeOOH} @ \mathrm{GO}$ catalyst has the potential to overcome the narrow application range of $\mathrm{pH}$ and the generation of iron sludge. Basing from the results of X-ray photoelectron spectroscopy and electron spin resonance (ESR) spectroscopy, the authors proposed the degradation mechanism of MB as follows. First, $\mathrm{MB}$ was adsorbed on the surface of $\beta-\mathrm{FeOOH} @ \mathrm{GO}$ through electrostatic interaction and $\pi-\pi$ stacking. Second, $\mathrm{H}_{2} \mathrm{O}_{2}$ reacted with $\mathrm{Fe}^{2+}$ generated through the photoreduction of $\mathrm{Fe}^{3+}$ on the catalyst surface to generate $\cdot \mathrm{OH}$. Third, GO guaranteed the increase in the active sites and the effective enrichment of MB molecules, which were further attacked by $\cdot \mathrm{OH}$. Fourth, GO effectively captured the photo-generated electrons from the semiconductor conduction band or the LUMO of the dye and quickly transferred them to the active site of $\beta$-FeOOH because of the heterojunction between $\beta-\mathrm{FeOOH}$ and GO. Finally, $\mathrm{Fe}^{3+}$ could react with $h \nu, \mathrm{H}_{2} \mathrm{O}_{2}$, or the transferred electrons and be reduced to $\mathrm{Fe}^{2+}$, facilitating $\mathrm{Fe}^{3+} / \mathrm{Fe}^{2+}$ circulation.

Table 1 summarizes the catalytic performance of some typical photo-Fenton catalysts based on 2D graphene/iron oxides and iron oxides. Obviously, graphene-based catalysts possess an obvious edge over those without graphene owing to the outstanding physical and chemical properties of graphene.

\section{D Graphene/Spinel Ferrites}

Spinel ferrites are face-centered cubic structured oxides $\left(\mathrm{MFe}_{2} \mathrm{O}_{4}, \mathrm{M}=\mathrm{Co}, \mathrm{Cu}, \mathrm{Zn}, \mathrm{Ni}, \mathrm{Mn}\right.$, etc.) that have been widely applied in magnetic resonance imaging, electronic equipment, processing heavy metal waste and chemical sensors [26]. The properties of spinel ferrites largely depend on the position, nature, and quantity of the metal incorporated in the structure. Apart from thermal and chemical stability, spinel ferrites often possess magnetic properties and superior light absorption. Many spinel ferrites, such as $\mathrm{ZnFe}_{2} \mathrm{O}_{4}$ and $\mathrm{NiFe}_{2} \mathrm{O}_{4}$, have a narrower band gap of $1.90-2.20 \mathrm{eV}$ than traditional photocatalysts, such as CdS $(2.40 \mathrm{eV})$ and $\mathrm{WO}_{3}(2.80 \mathrm{eV})$, suggesting their wider visible light absorption [39]. Spinel ferrites are effective photocatalysts and 
Table 1 Recent studies on 2D graphene/iron oxide-based photo-Fenton systems

\begin{tabular}{|c|c|c|c|c|c|c|c|c|}
\hline Catalyst & Light source & ${ }^{C} \mathrm{H}_{2} \mathrm{O}_{2}$ & $C_{\text {catalyst }}(\mathrm{g} / \mathrm{L})$ & $\mathrm{pH}$ & Pollutant & Efficiency & $\begin{array}{l}\text { Efficiency } \\
\text { without gra- } \\
\text { phene }\end{array}$ & References \\
\hline $\mathrm{GO}-\mathrm{Fe}_{2} \mathrm{O}_{3}$ & $\begin{array}{l}300 \mathrm{~W} \text { Dy } \\
\text { lamp, > } 420 \mathrm{~nm}\end{array}$ & $10 \mathrm{~mL} / \mathrm{L}$ & 1 & 3.65 & $\begin{array}{l}\mathrm{RhB}(100 \mathrm{~mL}, \\
100 \mathrm{mg} / \mathrm{L}) \text { and } \\
\text { 4-nitrophe- } \\
\text { nol }(100 \mathrm{~mL} \\
50 \mathrm{mg} / \mathrm{L})\end{array}$ & $\begin{array}{l}99 \% \text { and } 92 \% \\
\text { in } 80 \mathrm{~min}\end{array}$ & - & {$[37]$} \\
\hline$\alpha-\mathrm{Fe}_{2} \mathrm{O}_{3} @ \mathrm{GO}$ & $\begin{array}{l}300 \mathrm{~W} \text { Xe } \\
\text { lamp, > } 400 \mathrm{~nm}\end{array}$ & $10 \mathrm{~mL} / \mathrm{L}$ & 0.2 & $7.0 \pm 0.2$ & $\begin{array}{c}\mathrm{RhB}(50 \mathrm{~mL}, \\
50 \mathrm{mg} / \mathrm{L})\end{array}$ & $\begin{array}{l}92 \% \text { in } \\
150 \text { min }\end{array}$ & $\begin{array}{l}\sim 32 \% \text { in } \\
150 \text { min }\end{array}$ & [59] \\
\hline $\begin{array}{l}\mathrm{Fe}_{3} \mathrm{O}_{4} @ \mathrm{rGO} @ \\
\mathrm{TiO}_{2}\end{array}$ & $\begin{array}{l}300 \mathrm{~W} \text { Xe } \\
\text { lamp, > } 400 \mathrm{~nm}\end{array}$ & $0.176 \mathrm{~mol} / \mathrm{L}$ & 1.5 & Neutral & $\begin{array}{l}\text { MB } \\
\quad(50 \mathrm{ml}, 10 \mathrm{mg} / \mathrm{L})\end{array}$ & $\begin{array}{l}99 \% \text { in } \\
120 \mathrm{~min}\end{array}$ & - & {$[60]$} \\
\hline $\begin{array}{l}\text { Ammonia- } \\
\text { modified } \\
\text { graphene- } \\
\mathrm{Fe}_{3} \mathrm{O}_{4}\end{array}$ & $\begin{array}{l}\text { Sunlight within } \\
10 \text { am to } 2 \mathrm{pm} \\
\text { in Jorhat, } \\
\text { Assam, India } \\
(600-700 \mathrm{~W} / \\
\left.\mathrm{m}^{2}\right)\end{array}$ & $0.15 \mathrm{~mol} / \mathrm{L}$ & 0.5 & 7 & $\begin{array}{l}\text { Phenol, 2-nitro- } \\
\text { phenol and } \\
\text { 2-chlorophe- } \\
\text { nol (30 mL, } \\
0.4 \mathrm{mM})\end{array}$ & $\begin{array}{l}93.6 \% \text { in } \\
80 \mathrm{~min}, \\
98.8 \% \text { in } \\
50 \mathrm{~min}, \text { and } \\
98.1 \% \text { in } \\
60 \mathrm{~min}\end{array}$ & $\begin{array}{r}\text { Phenol: } 57 \% \\
\text { in } 120 \mathrm{~min}\end{array}$ & {$[61]$} \\
\hline $\mathrm{Fe}_{3} \mathrm{O}_{4} / \mathrm{GO}$ & $\begin{array}{l}300 \mathrm{~W} \text { Xe lamp, } \\
\text { AM } 1.5\end{array}$ & $24.0 \mathrm{~mL} / \mathrm{L}$ & - & 3.5 & $\begin{array}{c}\mathrm{MO}(50 \mathrm{~mL} \\
10 \mathrm{mg} / \mathrm{L})\end{array}$ & $98 \%$ in $30 \mathrm{~min}$ & $82 \%$ in $30 \mathrm{~min}$ & {$[20]$} \\
\hline $\begin{array}{l}\mathrm{Fe}_{3} \mathrm{O}_{4} @ \\
\text { hydrophilic } \\
\text { graphene }\end{array}$ & $\begin{array}{l}500 \mathrm{~W} \text { mercury } \\
\text { lamp }\end{array}$ & $24.0 \mathrm{~mL} / \mathrm{L}$ & 0.06 & 3.5 & $\begin{array}{c}\text { MO }(50 \mathrm{~mL} \\
10 \mathrm{mg} / \mathrm{L})\end{array}$ & $\begin{array}{r}87.7 \% \text { in } \\
30 \mathrm{~min}\end{array}$ & $\begin{array}{l}9.5 \% \text { in } \\
30 \mathrm{~min}\end{array}$ & {$[33]$} \\
\hline $\mathrm{Fe}_{3} \mathrm{O}_{4}-\mathrm{GO}$ & 500 W Xe lamp & $20 \mathrm{mg} / \mathrm{L}$ & 0.25 & 5.0 & $\begin{array}{l}\text { Phenol (500 mL, } \\
20 \mathrm{mg} / \mathrm{L})\end{array}$ & $\begin{array}{l}98.8 \% \text { in } \\
120 \text { min }\end{array}$ & $\begin{array}{l}73.7 \% \text { in } \\
120 \mathrm{~min}\end{array}$ & {$[34]$} \\
\hline $\begin{array}{l}\text { Graphene- } \\
\mathrm{Fe}_{3} \mathrm{O}_{4}\end{array}$ & 90 W UV lamp & $10 \mathrm{~mL} / \mathrm{L}$ & 0.2 & 4 & $\begin{array}{c}\text { MO }(100 \mathrm{~mL} \\
20 \mathrm{mg} / \mathrm{L})\end{array}$ & $\begin{array}{l}99.2 \% \text { in } \\
30 \mathrm{~min},\end{array}$ & $43 \%$ in $30 \mathrm{~min}$ & {$[62]$} \\
\hline $\begin{array}{l}\text { Pyrrolic } \\
\text { N-doped } \\
\mathrm{GO} / \mathrm{Fe}_{2} \mathrm{O}_{3}\end{array}$ & $\begin{array}{l}300 \mathrm{~W} \text { Xe } \\
\text { lamp, > } 420 \mathrm{~nm}\end{array}$ & - & 0.2 & - & $\begin{array}{c}\text { MB }(50 \mathrm{~mL}, \\
10 \mathrm{mg} / \mathrm{L})\end{array}$ & $\sim 70 \%$ in $2 \mathrm{~h}$ & $\begin{array}{l}\sim 48 \% \text { in } \\
\quad 120 \mathrm{~min}\end{array}$ & {$[32]$} \\
\hline$\alpha-\mathrm{Fe}_{2} \mathrm{O}_{3} @ \mathrm{GO}$ & $\begin{array}{r}100 \mathrm{~W} \text { mercury } \\
\text { lamp, } 365 \mathrm{~nm}\end{array}$ & $1.10 \mathrm{mmol} / \mathrm{L}$ & 0.25 & $3-12$ & $\begin{array}{l}\text { MO (400 mL, } \\
\quad 40 \mathrm{mg} / \mathrm{L})\end{array}$ & $\begin{array}{l}\sim 95 \% \text { in } \\
20 \text { min }\end{array}$ & $\begin{array}{r}\sim 78 \% \text { in } \\
20 \text { min }\end{array}$ & {$[31]$} \\
\hline $\begin{array}{l}\mathrm{ZnO}-\mathrm{Fe}_{3} \mathrm{O}_{4} / \\
\mathrm{rGO}\end{array}$ & $\begin{array}{l}300 \mathrm{~W} \text { Xe } \\
\text { lamp, }>420 \mathrm{~nm}\end{array}$ & $30 \mu \mathrm{mol} / \mathrm{L}$ & 0.4 & 7 & $\begin{array}{c}\mathrm{MB}(50 \mathrm{~mL}, \\
10 \mathrm{mg} / \mathrm{L})\end{array}$ & $\begin{array}{l}\sim 97 \% \text { in } \\
150 \text { min }\end{array}$ & $\begin{array}{l}\sim 41 \% \text { in } \\
150 \text { min }\end{array}$ & {$[27]$} \\
\hline$\gamma-\mathrm{Fe}_{2} \mathrm{O}_{3} / \mathrm{GO}$ & $\begin{array}{l}250 \mathrm{~W} \text { mercury } \\
\text { lamp }\end{array}$ & $50.0 \mathrm{~mL} / \mathrm{L}$ & 0.2 & $4.2-10.2$ & $\begin{array}{c}\text { MB }(50 \mathrm{~mL}, \\
50 \mathrm{mg} / \mathrm{L})\end{array}$ & $\begin{array}{l}99 \% \text { in } \\
100 \text { min }\end{array}$ & $\begin{array}{l}\sim 88 \% \text { in } \\
120 \text { min }\end{array}$ & {$[63]$} \\
\hline $\begin{array}{l}\mathrm{Au}-\mathrm{Fe}_{3} \mathrm{O}_{4} / \mathrm{gra}- \\
\text { phene }\end{array}$ & 40 W UV-C lamp & $40 \mathrm{~mL} / \mathrm{L}$ & - & 7 & $\begin{array}{l}\text { MB }(100 \mathrm{~mL}, \\
20 \mathrm{mg} / \mathrm{L})\end{array}$ & $\begin{array}{l}100 \% \text { in } \\
120 \mathrm{~min}\end{array}$ & - & {$[64]$} \\
\hline$\beta-\mathrm{FeOOH} / \mathrm{GO}$ & $\begin{array}{l}125 \mathrm{~W} \text { mercury } \\
\text { lamp, } 365 \mathrm{~nm}\end{array}$ & $1.10 \mathrm{mmol} / \mathrm{L}$ & 0.25 & $2.67-12.11$ & $\begin{array}{l}\mathrm{MB}(400 \mathrm{~mL}, \\
40 \mathrm{mg} / \mathrm{L})\end{array}$ & $\begin{array}{r}99.7 \% \text { in } \\
60 \mathrm{~min}\end{array}$ & $\begin{array}{r}96.1 \% \text { in } \\
60 \mathrm{~min}\end{array}$ & {$[35]$} \\
\hline
\end{tabular}

active in neutral and alkaline Fenton systems. Loading spinel ferrites on graphene hampers the agglomeration of spinel ferrite nanoparticles and the leaching of poisonous ions. Given the large specific surface area and robust light absorption of graphene, the graphene/spinel ferrite composites ought to perform enhanced catalytic activity in photoFenton reactions.

Zinc ferrite $\left(\mathrm{ZnFe}_{2} \mathrm{O}_{4}\right)$ is characterized by visible light response, light stability, and low cost. Owing to the narrow band gap of $1.90 \mathrm{eV}, \mathrm{ZnFe}_{2} \mathrm{O}_{4}$ is particularly popular in solar energy conversion, photocatalysis, and photochemical hydrogen production. Early in 2011, Fu and Wang [25] synthesized $\mathrm{ZnFe}_{2} \mathrm{O}_{4}$-graphene by using a one-step hydrothermal method readily and employed it for the photo-Fenton degradation of $\mathrm{MB}$ with visible light. The FESEM image in Fig. 5a shows that $\mathrm{ZnFe}_{2} \mathrm{O}_{4}$ nanoparticles $(7-10 \mathrm{~nm})$ were uniformly loaded on the surface of exfoliated graphene sheets. The $\mathrm{ZnFe}_{2} \mathrm{O}_{4}$-graphene with $20 \mathrm{wt} \%$ graphene exhibited greater photo-Fenton activity (99\% degradation of MB in $90 \mathrm{~min}$ ) than pristine $\mathrm{ZnFe}_{2} \mathrm{O}_{4}(20 \%$ degradation of $\mathrm{MB}$ in $90 \mathrm{~min}$ ). Probing the cause of the great enhancement, electrochemical impedance spectroscopy measurements were performed to identify the electrical resistivity. As shown in Fig. 5b, the Nyquist curves of $\mathrm{ZnFe}_{2} \mathrm{O}_{4}$-graphene possessed a much smaller radius than those of $\mathrm{ZnFe}_{2} \mathrm{O}_{4}$ and $\mathrm{GO}$, implying lower electrical resistance and higher electronic mobility. In short, graphene is a unique 2D material with zero band gap and $\pi$-conjugation structure. On its surface, 

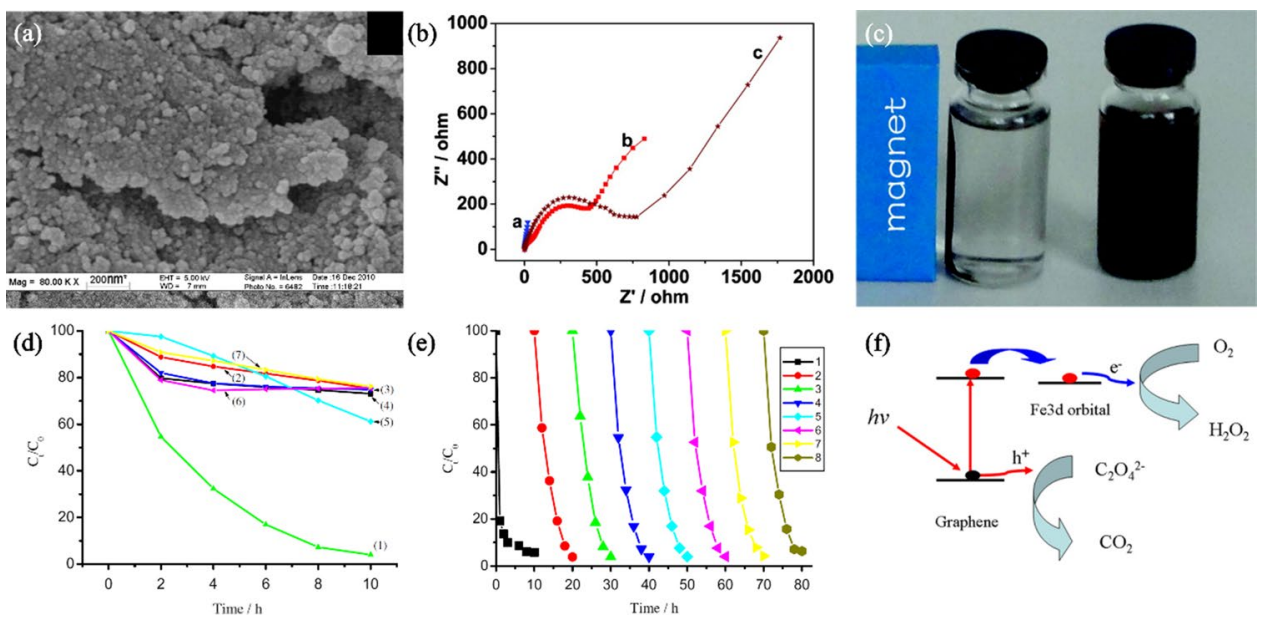

Fig. 5 a FESEM images of $\mathrm{ZnFe}_{2} \mathrm{O}_{4}-\mathrm{G}$ (0.2); b EIS of (a) $\mathrm{ZnFe}_{2} \mathrm{O}_{4}-\mathrm{G}(0.2)$, (b) pure $\mathrm{ZnFe}_{2} \mathrm{O}_{4}$, and (c) $\mathrm{GO}$; and $\mathbf{c}$ images of $\mathrm{ZnFe}_{2} \mathrm{O}_{4}-\mathrm{G}(0.2)$ suspension with and without a magnetic field. Reproduced with permission from Ref. [25]. Copyright 2011 American Chemical Society. d Photo-Fenton degradation of MB. Initial conditions are as follows: (1) $\mathrm{MB}+\mathrm{GO}-\mathrm{NiFe}_{2} \mathrm{O}_{4}+1.0 \mathrm{mmol} / \mathrm{L}$ $\mathrm{H}_{2} \mathrm{C}_{2} \mathrm{O}_{4}$ + visible light; (2) $\mathrm{MB}+\mathrm{NiFe}_{2} \mathrm{O}_{4}+1.0 \quad \mathrm{mmol} / \mathrm{L}$ $\mathrm{H}_{2} \mathrm{C}_{2} \mathrm{O}_{4}$ + visible light; (3) $\mathrm{MB}+\mathrm{GO}-\mathrm{NiFe}_{2} \mathrm{O}_{4}+\mathrm{H}_{2} \mathrm{C}_{2} \mathrm{O}_{4} \quad$ in

the carriers appeared as massless fermions. Thus, the photogenerated electrons produced by $\mathrm{ZnFe}_{2} \mathrm{O}_{4}$ could quickly transfer from its conduction band to graphene, improving the activity of photo-Fenton reactions. Moreover, the catalysts were easily recovered because of the magnetic property of $\mathrm{ZnFe}_{2} \mathrm{O}_{4}$ (Fig. 5c). The subsequent unchanged degradation rate of $\mathrm{MB}$ for 10 cycles exemplified the catalytic stability of $\mathrm{ZnFe}_{2} \mathrm{O}_{4}$-graphene.

With a narrow band gap of $2.10 \mathrm{eV}, \mathrm{NiFe}_{2} \mathrm{O}_{4}$ has the potential to be a photocatalyst because of its stable structure, high electrical resistance, and photochemical stability. The ferromagnetism stemming from its magnetic moment of the antiparallel spin between the $\mathrm{Ni}^{2+}$ ion and the $\mathrm{Fe}^{3+}$ ion reduces the cost of catalyst recovery [40]. Liu et al. [41] loaded $\mathrm{NiFe}_{2} \mathrm{O}_{4}$ on $\mathrm{GO}$ sheets through a facile hydrothermal method and performed the degradation of $\mathrm{MB}$ with the addition of a GO- $\mathrm{NiFe}_{2} \mathrm{O}_{4}$ composite, visible light, and oxalic acid. The authors selected oxalic acid rather than $\mathrm{H}_{2} \mathrm{O}_{2}$ for the increased light absorption because of the formation of ferric oxalate and the large rate constant of the rate-determining step of the ferric oxalate-based photo-Fenton system. The photo-Fenton experiment (Fig. 5d) showed that the photo-Fenton degradation rate of $\mathrm{MB}$ with $\mathrm{GO}-\mathrm{NiFe}_{2} \mathrm{O}_{4}$ reached $96.2 \%$ after $10 \mathrm{~h}$, whereas that of $\mathrm{MB}$ with $\mathrm{NiFe}_{2} \mathrm{O}_{4}$ was $24.6 \%$, which was almost same as the Fenton degradation rate of $\mathrm{MB}$ in the dark with $\mathrm{GO}-\mathrm{NiFe}_{2} \mathrm{O}_{4}$. In addition, the mechanical mixture of $\mathrm{GO}$ and $\mathrm{NiFe}_{2} \mathrm{O}_{4}$ demonstrated no obvious catalytic enhancement over $\mathrm{NiFe}_{2} \mathrm{O}_{4}$. These results suggested that the effective combination of $\mathrm{GO}$ and $\mathrm{NiFe}_{2} \mathrm{O}_{4}$ the dark; (4) $\mathrm{MB}+\mathrm{GO}-\mathrm{NiFe}_{2} \mathrm{O}_{4}+$ visible light; (5) $\mathrm{MB}+\mathrm{GO}-$ $\mathrm{NiFe}_{2} \mathrm{O}_{4}$ in the dark; (6) $\mathrm{MB}+\mathrm{H}_{2} \mathrm{C}_{2} \mathrm{O}_{4}$ in the dark; and (7) $\mathrm{MB}+\mathrm{GO}+\mathrm{NiFe}_{2} \mathrm{O}_{4}+\mathrm{H}_{2} \mathrm{C}_{2} \mathrm{O}_{4}+$ visible light; $\mathbf{e}$ cyclic tests of $0.10 \mathrm{~g}$ of GO-NiFe ${ }_{2} \mathrm{O}_{4}$ catalyst in $50.0 \mathrm{~mL}$ of solution containing $20.0 \mathrm{mg} / \mathrm{L}$ $\mathrm{MB}$ in the presence of $1.0 \mathrm{mmol} / \mathrm{L}$ oxalic acid; $\mathbf{f}$ photochemical process mediated by graphene in the $\mathrm{GO}-\mathrm{NiFe}_{2} \mathrm{O}_{4}$ hybrid material. Reproduced with permission from Ref. [41]. Copyright 2013 Elsevier Ltd.

achieved such an efficient catalytic performance and that GO increased the light absorbance rather than degraded MB by itself. A recycling degradation experiment was also carried out readily because of the ferromagnetism of $\mathrm{NiFe}_{2} \mathrm{O}_{4}$. Results revealed that the degradation rate remained above 90\% even after eight cycles (Fig. 5e). A schematic of the degradation is provided in Fig. $5 \mathrm{f}$.

Researchers have also disclosed the effect of GO on other spinel ferrite-based photo-Fenton systems, such as manganese ferrite $\left(\mathrm{MnFe}_{2} \mathrm{O}_{4}\right)$ and cobalt ferrite $\left(\mathrm{CoFe}_{2} \mathrm{O}_{4}\right)$. $\mathrm{MnFe}_{2} \mathrm{O}_{4}$ is also a magnetically separable material. With multiple absorption bands at 295, 430, 576, and $745 \mathrm{~nm}$, $\mathrm{MnFe}_{2} \mathrm{O}_{4}$ broadly responds to UV and visible light. Unfortunately, $\mathrm{MnFe}_{2} \mathrm{O}_{4}$ itself does not exhibit photocatalytic activity under visible light excitation [42]. Zhou et al. [42] therefore combined it with graphene for enhanced light absorption. Under visible light irradiation, the degradation rate of $\mathrm{NH}_{3}-\mathrm{N}$ solution with graphene-manganese ferrite $\left(\mathrm{rG}-\mathrm{MnFe}_{2} \mathrm{O}_{4}\right)$ in $10 \mathrm{~h}$ was $92 \%$, which was much higher than that with $\mathrm{MnFe}_{2} \mathrm{O}_{4}$ (51.5\%). The ameliorated light absorption caused by the combination of graphene and $\mathrm{MnFe}_{2} \mathrm{O}_{4}$ and the improved pollutant adsorption resulting from the increase in the specific surface area from $3.99 \mathrm{~m}^{2} / \mathrm{g}$ of $\mathrm{rG}$ to $7.30 \mathrm{~m}^{2} / \mathrm{g}$ of $\mathrm{rG}-\mathrm{MnFe}_{2} \mathrm{O}_{4}$ contributed to the intriguing photo-Fenton catalytic activity. $\mathrm{CoFe}_{2} \mathrm{O}_{4}$ is characterized by its narrow band gap, low toxicity, natural abundance, and low cost. He and $\mathrm{Lu}$ [43] synthesized $\mathrm{rGO} / \mathrm{CoFe}_{2} \mathrm{O}_{4}$ hybrids through a hydrothermal method, in which $\mathrm{CoFe}_{2} \mathrm{O}_{4}$ nanoparticles were uniform particles with an average size 
of $\sim 17 \mathrm{~nm}$ loaded on the surface of rGO. Malachite green was taken as the model pollutants for the photo-Fenton reactions at neutral $\mathrm{pH}$. The introduction of rGO improved the degradation rate from $\sim 79$ to $\sim 99 \%$ in $30 \mathrm{~min}$, corresponding to the pseudo-first-order kinetic rate constants of 11.20 and $18.42 \mathrm{~h}^{-1}$. The high valence band of $\mathrm{CoFe}_{2} \mathrm{O}_{4}$ enabled the photo-generated electrons to transfer spontaneously from $\mathrm{CoFe}_{2} \mathrm{O}_{4}$ to $\mathrm{rGO}$, thereby increasing photo-Fenton activity.

\section{D Graphene/Iron-Based Metal Organic Frameworks}

Metal organic frameworks (MOFs) are crystalline porous materials composed of multidentate organic ligands and metal ions or clusters. Given their large specific surface area, MOFs have been widely used in gas storage, adsorption, and separation $[44,45]$. In addition, MOFs are extensively responsive to UV and visible light owing to their ligand-metal charge transfer (LMCT) property, making them promising candidates as novel photocatalysts. In particular, iron-based MOFs have attracted wide attention because of their $\mathrm{Fe}_{3}-\mu_{3}$-oxo clusters and low toxicity [46]. However, the application of MOFs as photo-induced catalysts is limited by the poor separation and migration of photo-induced carriers, whose common amelioration methods include surface modification and doping [47]. Considering the preeminent visible light absorption and electron mobility of graphene, $\mathrm{MOF}$ materials could be loaded on graphene to prepare hybrid photo-Fenton catalysts. The introduction of graphene is also believed to improve structural stability and inhibit photocorrosion [48].

In 2018, Liu et al. [47] polymerized ultrathin GO on the surface of MIL-88A(Fe) to prepare MIL-88A(Fe)/GO. As shown in the SEM image in Fig. 6a, MIL-88A(Fe) appeared as needle-shaped nanorods $1-3 \mu \mathrm{m}$ long with high crystallinity and GO distributed evenly on the surface. UV-Vis DRS (Fig. 6b) revealed that all the samples absorbed light effectively at the wavelength of $200-600 \mathrm{~nm}$. Concerning pristine MIL-88A $(\mathrm{Fe})$, the characteristic absorption peak at about $250 \mathrm{~nm}$ was ascribed to the LMCT of O(II) to Fe(III), and the bands at $300-500 \mathrm{~nm}$ were attributed to the $\mathrm{d}-\mathrm{d}$ transition of $\mathrm{Fe}(\mathrm{III})$. The absorption edges of MIL-88A(Fe)/ $\mathrm{GO}$ and MIL- $88 \mathrm{~A}(\mathrm{Fe}) / \mathrm{GO}$ were similar, but the introduction of GO considerably increased the absorption intensity, especially that in the visible light area, implying increased photoFenton catalytic ability. The results in the photo-Fenton degradation of $\mathrm{RhB}$ were consistent with the speculation. The
Fig. 6 a SEM image of MIL$88 \mathrm{~A}(\mathrm{Fe}) / \mathrm{GO}$; b UV-Vis DRS spectra of MIL-88A(Fe) and MIL-88A(Fe)/GO nanocomposites. Reproduced with permission from Ref. [47]. Copyright 2017 Elsevier B.V. c-e Separation of the GO/MIL-88A(Fe) membrane for $\mathrm{MB}$ solution; $\mathbf{f}-\mathbf{h}$ photo-Fenton self-cleaning to degrade accumulated MB molecules. Reproduced with permission from Ref. [46]. Copyright 2019 Elsevier B.V.
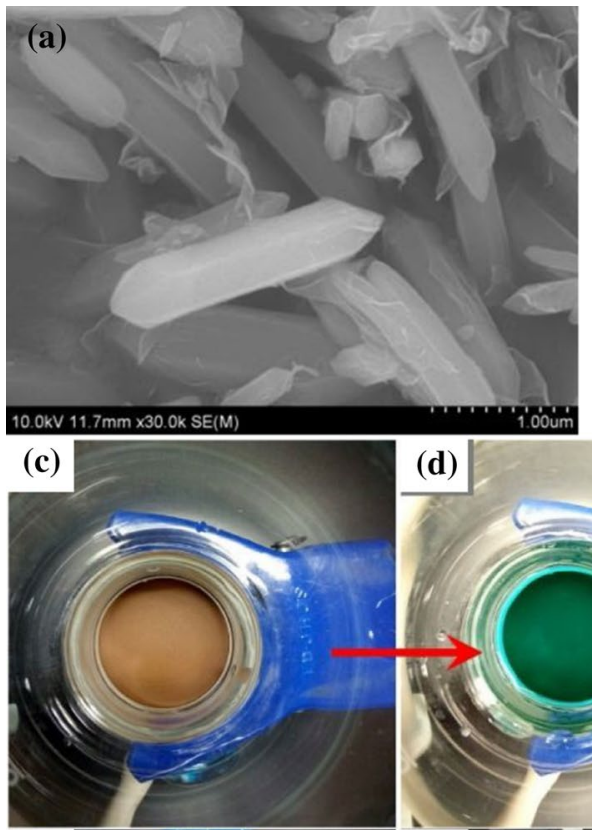

(h)

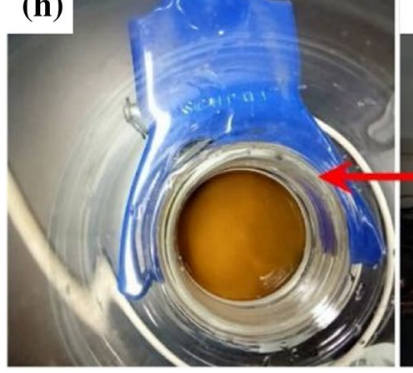

(d)

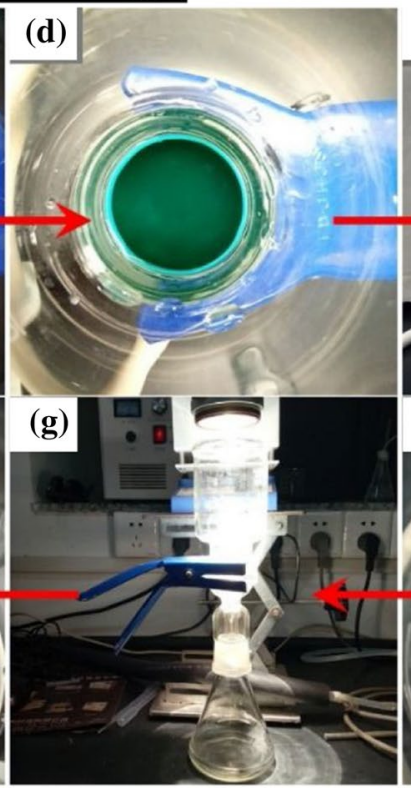

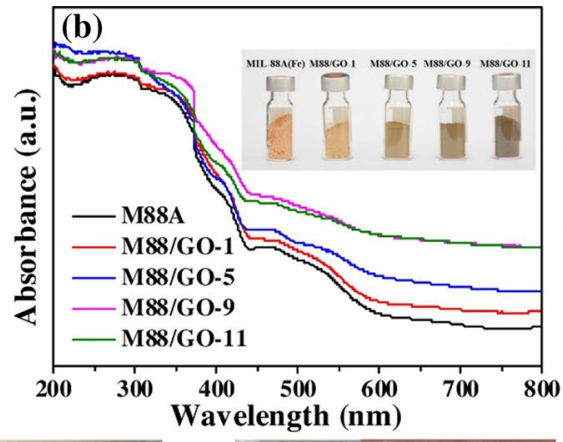

(e)

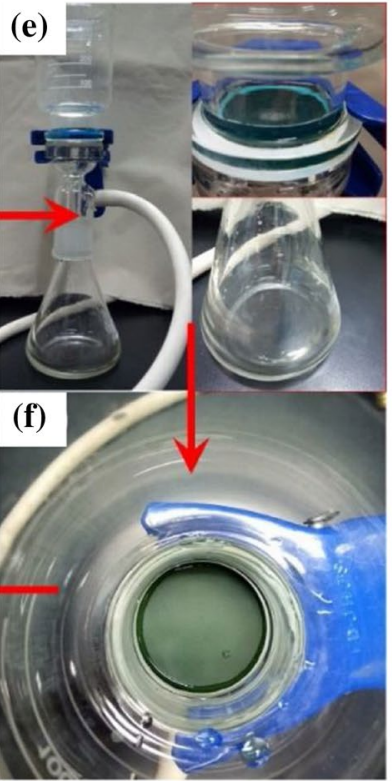


pseudo-first-order kinetic rate constant of the degradation of $\mathrm{RhB}$ with MIL-88A(Fe)/GO was $0.0645 \mathrm{~min}^{-1}$, which was 8.4 times higher than that with MIL- $88 \mathrm{~A}(\mathrm{Fe})$. The composite retained its high photo-Fenton performance in a wide $\mathrm{pH}$ range of 1-9 with no significant loss of catalytic ability after five cycles, suggesting the wide $\mathrm{pH}$ application range and stable catalytic stability of the composite. Xie et al. [46] reported a facile vacuum filtration strategy to prepare a $\mathrm{GO} /$ MIL-88A(Fe) membrane for the separation and degradation of MB. The introduction of GO modulated the 2D nanochannel in the membrane, enabling high flux and efficient separation to be mutually compatible. Concomitant light absorption enhancement contributed to the photo-Fenton reaction for the removal of contaminants clogging the interior of the membrane. The degradation of MB could be intuitively observed in Fig. 6c-h. After the separation (Fig. 6c-e), the residue of MB inside the membrane (Fig. 6f) was completely eliminated after the photo-Fenton process with visible light irradiation in $30 \mathrm{~min}$ (Fig. 6g, h). The mechanism conjectured from the results of ESR spectra is as follows. First, GO/MIL-88A(Fe) membrane generated electron-hole pairs when irradiated by visible light, in which holes directly oxidized organic pollutants and electrons migrating onto the $\mathrm{GO}$ surface promoted the decomposition of $\mathrm{H}_{2} \mathrm{O}_{2}$ into $\cdot \mathrm{OH}$. Meanwhile, electrons could also be captured by oxygen to form superoxide radicals $\left(\mathrm{O}_{2}^{-}\right)$on the membrane surface, and the generated $\cdot \mathrm{OH}$ and $\mathrm{O}_{2}^{--}$completely degraded organic pollutants. Within the catalyst, $\mathrm{Fe}-\mathrm{O}$ clusters also facilitated the decomposition of $\mathrm{H}_{2} \mathrm{O}_{2}$ through Fenton-like reactions, and active sites provided by GO nanosheets enhanced the photo-Fenton catalytic ability.
Gong et al. [44] used MIL-100(Fe) to synthesize an $\mathrm{Fe}_{3} \mathrm{O}_{4} @ \mathrm{GO} @ \mathrm{MIL}-100(\mathrm{Fe})$ magnetic catalyst with a core-shell structure for the degradation of 2,4-dichlorophenl (2,4-DCP). Figure 7a-c displays the microstructures of $\mathrm{Fe}_{3} \mathrm{O}_{4}, \mathrm{Fe}_{3} \mathrm{O}_{4} @ \mathrm{GO}$, and $\mathrm{Fe}_{3} \mathrm{O}_{4} @ \mathrm{GO} @ \mathrm{MIL}-100(\mathrm{Fe})$, respectively. $\mathrm{Fe}_{3} \mathrm{O}_{4}$ is spherical with a rough surface whose diameter is $300-350 \mathrm{~nm}$. After loading GO, a rugate surface texture appeared on $\mathrm{Fe}_{3} \mathrm{O}_{4} @ \mathrm{GO}$ because of the GO shell. Further wrapped with MIL-100(Fe), the surface became rougher with the MIL-100(Fe) shell, contributing to the spectacular specific surface area of $1048.1 \mathrm{~m}^{2} / \mathrm{g}$, which was much larger than that of $\mathrm{Fe}_{3} \mathrm{O}_{4} @$ GO $\left(79.4 \mathrm{~m}^{2} / \mathrm{g}\right)$. The degradation rates of 2,4-DCP in the photo-Fenton system with $\mathrm{Fe}_{3} \mathrm{O}_{4} @ \mathrm{GO} @ \mathrm{MIL}-100(\mathrm{Fe})$ exceeded $90 \%$, and the total organic carbon (TOC) removal rates reached $50 \%$ in four cycles. Coupled with the inherent magnetism, the $\mathrm{Fe}_{3} \mathrm{O}_{4} @ \mathrm{GO} @ \mathrm{MIL}-100(\mathrm{Fe})$ hybrid catalyst displayed its great potential for practical recycling. Analysis of the ESR spectra (Fig. 7d, e) revealed that the peaks of DMPO-HO with an intensity ratio of 1:2:2:1 and the peaks of DMPO- $\mathrm{O}_{2}^{--}$with an intensity ratio of $1: 1: 1: 1$ were strong, suggesting that more $\cdot \mathrm{OH}$ and $\mathrm{O}_{2}^{--}$radicals were generated in the system. Combining additional PL spectra and photocurrent response measurements, the authors proposed the possible mechanism. When irradiated by visible light, photo-generated electrons were generated in MIL-100(Fe), captured by GO rapidly, and transferred to $\mathrm{Fe}_{3} \mathrm{O}_{4}$ and $\mathrm{Fe}^{3+}$ in MIL-100( $\left.\mathrm{Fe}\right)$, promoting the reduction of $\mathrm{Fe}^{3+}$ to $\mathrm{Fe}^{2+}$. The increased $\mathrm{O}_{2}^{--}$from the dissolved oxygen and $\cdot \mathrm{OH}$ promoted the degradation of 2,4-DCP.
Fig. 7 TEM images of $\mathbf{a ~} \mathrm{Fe}_{3} \mathrm{O}_{4}$, b $\mathrm{Fe}_{3} \mathrm{O}_{4} @ \mathrm{GO}$, and $\mathbf{c} \mathrm{Fe}_{3} \mathrm{O}_{4} @$ GO@MIL-100(Fe); ESR spectra of $\mathbf{d}$ DMPO-HO adducts and $\mathbf{e}$ DMPO- $\mathrm{O}_{2}^{-}$adducts in the photo-Fenton system with $\mathrm{Fe}_{3} \mathrm{O}_{4}, \mathrm{Fe}_{3} \mathrm{O}_{4} @ \mathrm{GO}, \mathrm{MIL}-$ $100(\mathrm{Fe}), \mathrm{Fe}_{3} \mathrm{O}_{4} @ \mathrm{MIL}-100(\mathrm{Fe})$ and $\mathrm{Fe}_{3} \mathrm{O}_{4} @ \mathrm{GO} @ \mathrm{MIL}-100(\mathrm{Fe})$ under visible light irradiation. Reproduced with permission from Ref. [44]. Copyright 2019 Elsevier B.V.

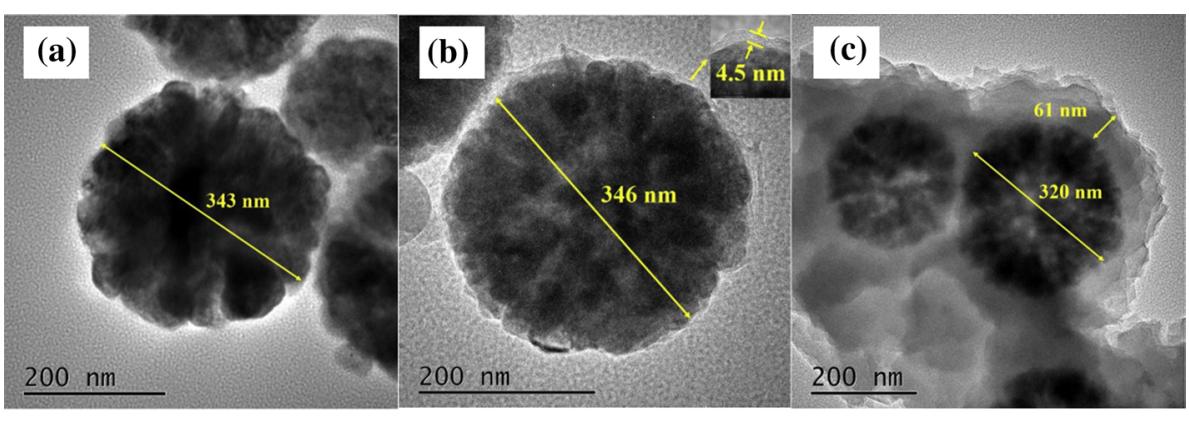

(d)

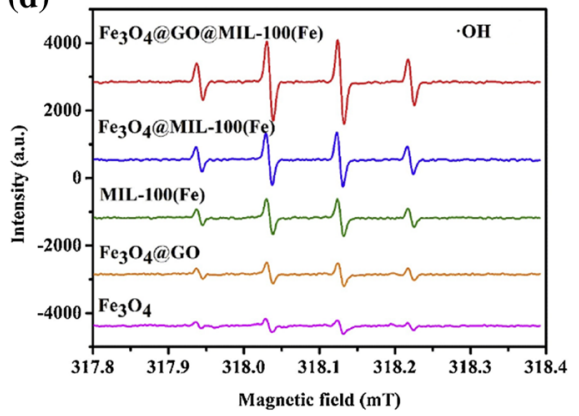

(e)

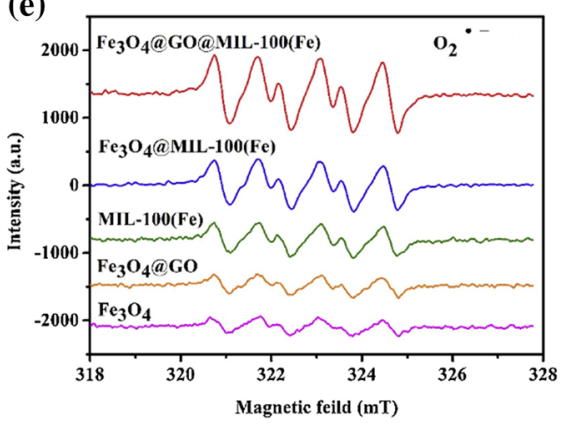


The aforementioned papers on 2D graphene/iron oxides, 2D graphene/spinel ferrites, and 2D graphene/iron-based MOFs suggested the following common points: (1) graphene materials exhibit excellent light absorption, pollutants adsorption, and electron transport capabilities, thus improving the efficiency of photo-Fenton systems; (2) graphene is competent for the firm support of photo-Fenton catalysts that effectively inhibit the agglomeration of active components; (3) researchers tend to prepare iron-containing catalysts and increase the reaction $\mathrm{pH}$, thus broadening the $\mathrm{pH}$ conditions of the reaction and hampering the formation of iron sludge; and (4) magnetic materials are becoming popular in photo-Fenton systems because of easy recycling. However, even magnetic $2 \mathrm{D}$ graphene-based materials are difficult to be separated from the sewage sludge under the actual scenario. The incidental agglomeration of 2D graphene-based composite catalysts after the reaction and the dissolution of active substances also leads to irreversible deactivation. Consequently, researchers have focused on using 3D graphene-based materials.

\section{Three-Dimensional Graphene-Based Photo-Fenton Systems}

Although 2D graphene-based materials have many advantages, their lamellar structures easily agglomerate, which reduces the specific surface area and active sites. Small 2D graphene-based catalysts may enter the aquatic environment, leading to potential pollution [38]. Fortunately, 3D graphene aerogel and hydrogel materials obtained by the self-assembly of 2D graphene materials not only inherit the intriguing properties of $2 \mathrm{D}$ graphene-based materials but also are easily separated from the aqueous solution. The special 3D porous structure also provides a myriad of channels for the transport and diffusion of reactants. Accordingly, 3D graphene materials have been widely applied in sensors [49], energy storage [50], and pollutant control [21].

\section{Three-Dimensional Graphene-Based Aerogels}

As a novel carrier, the graphene aerogel is characterized by a porous 3D framework, large specific surface area, excellent electron mobility, mechanism stability, and great adsorption [51]. After the self-assembly of 2D graphene materials, the original contact resistance between graphene sheets disappears, accelerating the electron transport. In addition, the intricate and conductive graphene network renders a multitude of paths for transport and diffusion [38]. Consequently, graphene aerogels have been widely investigated in sensors, oil absorption, energy storage, and catalysis [52]. As early as 2015, Qiu et al. [21] applied graphene aerogels in photonFenton reactions and laid a solid foundation for subsequent research in the synthetic method. In general, metallic oxide nanoparticles, conductive polymers, or other carbon materials are introduced to effectively regulate the nanostructure and function of graphene aerogels [51], which are discussed as follows.

The metallic oxide nanoparticles on graphene aerogels function as the active sites in photo-Fenton reactions. In addition, graphene aerogels offer 3D support for the high dispersion of metallic oxide nanoparticles on the graphene surface. Qiu et al. [21] first reported the application of $\mathrm{Fe}_{2} \mathrm{O}_{3}$ on graphene aerogels $\left(\mathrm{Fe}_{2} \mathrm{O}_{3} / \mathrm{GAs}\right)$ in photo-Fenton in 2015. The Stöber-like method was adopted to grow $\mathrm{Fe}_{2} \mathrm{O}_{3}$ nanocrystals in situ on graphene aerogels. Figure 8a displays the macroscopic structure of $\mathrm{Fe}_{2} \mathrm{O}_{3} / \mathrm{GAs}$ after a hydrothermal process, whose size could be easily modulated by altering the vessel. The $\mathrm{Fe}_{2} \mathrm{O}_{3} / \mathrm{GA}$ material possessed ultra-light mass characteristics and very low density $\left(8 \mathrm{mg} / \mathrm{cm}^{3}\right)$ despite containing $18.3 \mathrm{wt} \% \mathrm{Fe}_{2} \mathrm{O}_{3}$ nanocrystals. Figure $8 \mathrm{~b}$ shows that $\mathrm{Fe}_{2} \mathrm{O}_{3} / \mathrm{GAs}$ had a 3D hierarchical macroporous structure, where granular $\mathrm{Fe}_{2} \mathrm{O}_{3}$ nanocrystals were inserted into the graphene skeleton without any observable agglomeration. The TEM image in Fig. 8c demonstrates that $\mathrm{Fe}_{2} \mathrm{O}_{3}$ nanoparticles, mostly in the size of $25 \mathrm{~nm}$, were highly dispersed on the graphene surface. The consistent absence of agglomeration suggested that the Stöber-like approach was particularly conducive for the in situ growth of highly dispersed $\mathrm{Fe}_{2} \mathrm{O}_{3}$ nanocrystals on graphene aerogels. In addition, the mechanical strength of $\mathrm{Fe}_{2} \mathrm{O}_{3}$ /GAs was proved preeminent, as shown in Fig. 8d. It could withstand continuous compression for dozens of times, after which $\mathrm{Fe}_{2} \mathrm{O}_{3} / \mathrm{GAs}$ was almost completely expanded, indicating the great elasticity and preeminent mechanical strength. The stress-strain curve also indicated the same conclusion, and the diagrams of the sandwich biscuit-like structure are shown in Fig. 8e. The catalytic property of $\mathrm{Fe}_{2} \mathrm{O}_{3} /$ GAs in photo-Fenton reactions was also satisfying. Comparison of the photo-Fenton degradation of $\mathrm{MO}$ (Fig. 9a) showed that $\mathrm{Fe}_{2} \mathrm{O}_{3}$ and $\mathrm{Fe}_{2} \mathrm{O}_{3} / 2 \mathrm{D}$-graphene $\left(\mathrm{Fe}_{2} \mathrm{O}_{3} / \mathrm{GR}\right)$ suffered rapid deactivation after the two cycles of degradation owing to iron leaching. Although the amounts and particle sizes of $\mathrm{Fe}_{2} \mathrm{O}_{3}$ in $\mathrm{Fe}_{2} \mathrm{O}_{3} / \mathrm{GR}$ and $\mathrm{Fe}_{2} \mathrm{O}_{3} / \mathrm{GAs}$ were highly similar, the degradation rate in the $\mathrm{Fe}_{2} \mathrm{O}_{3}$ /GAs photo-Fenton system did not change appreciably even after 10 cycles because of its tough 3D network structure, which precluded iron leaching. This proposed reason was validated by $\mathrm{Fe}^{2+}$ capture experiments, where 1,10-phenanthroline monohydrate (Phen) was employed to capture the dissolved $\mathrm{Fe}^{2+}$ ions after degradation (Fig. 9b). The dissolution of $\mathrm{Fe}^{2+}$ in $\mathrm{Fe}_{2} \mathrm{O}_{3}$ was much higher than that in $\mathrm{Fe}_{2} \mathrm{O}_{3} / \mathrm{GAs}$, which reacted with $\mathrm{OH}^{-}$to form $\mathrm{Fe}(\mathrm{OH})_{3}$ and impeded the $\mathrm{Fe}^{3+} / \mathrm{Fe}^{2+}$ circulation. Moreover, $\mathrm{Fe}_{2} \mathrm{O}_{3} / \mathrm{GAs}$ exhibited excellent photo-Fenton activity in a wide $\mathrm{pH}$ range of 3.5-9.0 (Fig. 9c), but pristine $\mathrm{Fe}_{2} \mathrm{O}_{3}$ was gradually deactivated under neutral conditions with the 
Fig. 8 a $\mathrm{Fe}_{2} \mathrm{O}_{3} / \mathrm{GAs}$ with variable shapes prepared by changing the reaction vessel (reaction vessel increases from right to left); $\mathbf{b}$ FESEM and $\mathbf{c}$ TEM images of $\mathrm{Fe}_{2} \mathrm{O}_{3} / \mathrm{GAs} ; \mathbf{d}$ compression test of $\mathrm{Fe}_{2} \mathrm{O}_{3} / \mathrm{GAs}$; and e structure of $\mathrm{Fe}_{2} \mathrm{O}_{3} / \mathrm{GAs}$ during the compression test. Reproduced with permission from Ref. [21]. Copyright 2015 The Royal Society of Chemistry

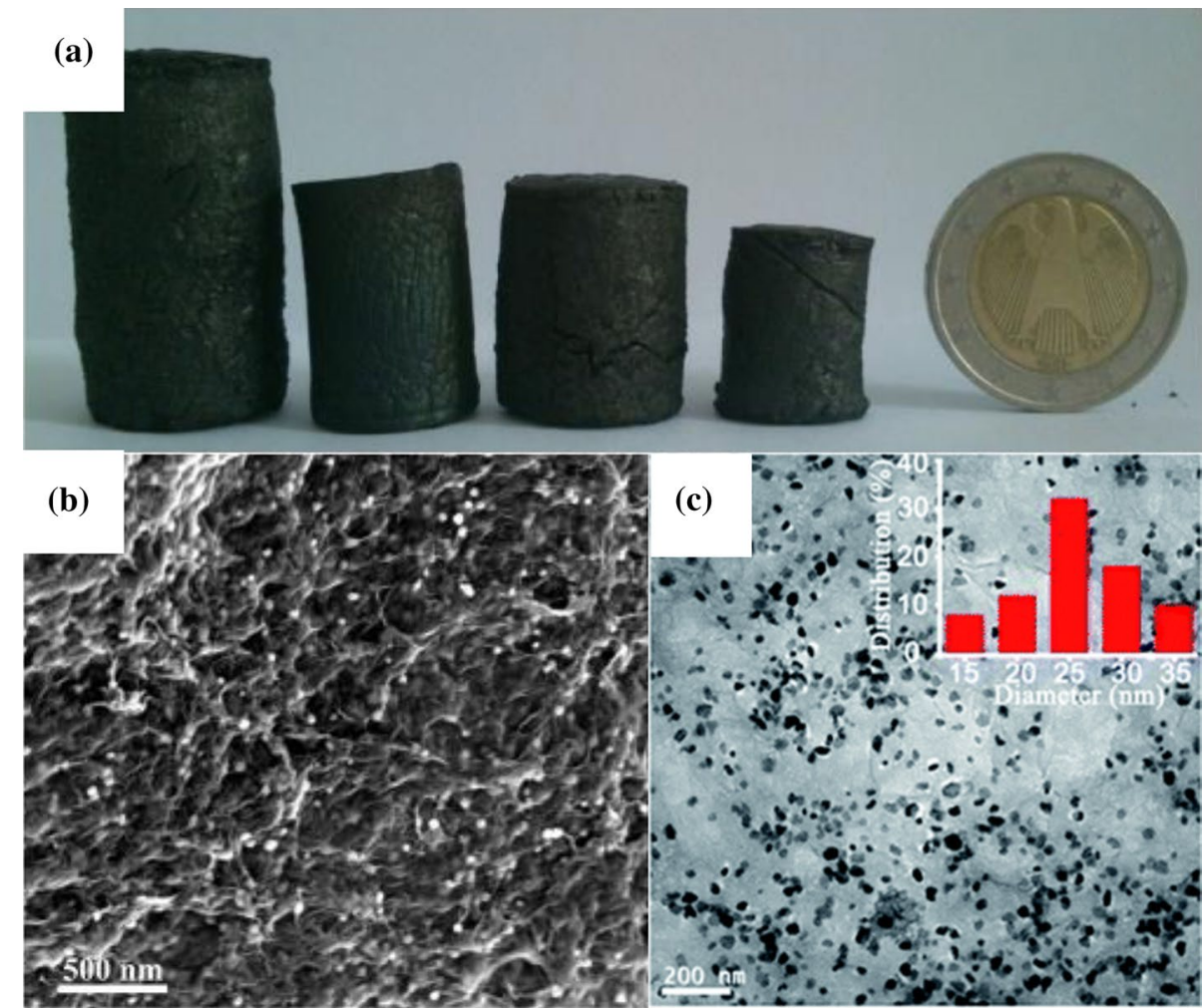

(d)

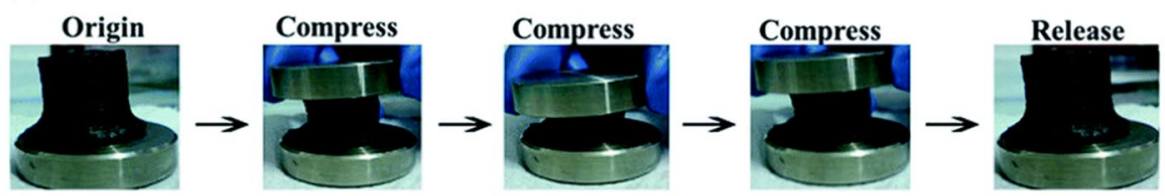

(e)
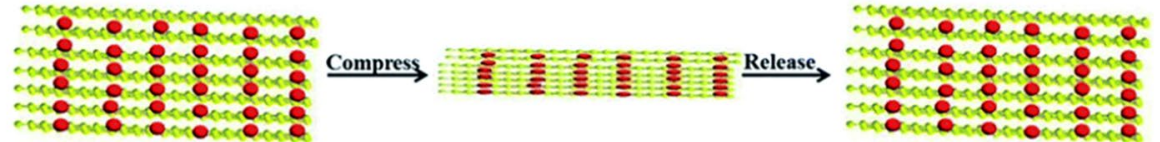

increase in the number of cycles because of the iron sludge covered on the surface (Fig. 9d). Figure 9e illustrates the proposed mechanism, which is similar to that in 2D graphene-based photo-Fenton systems.

Polymers, such as polypyrrole, cellulose, and polyvinyl alcohol, have been exploited as cross-linkers for the selfassembly of GO nanosheets, modulating the structures and properties of graphene aerogels. Tong et al. [53] prepared a reduced graphene oxide/Prussian blue/polypyrrole aerogel (rGO/PB/PPy) hybrid catalyst for photo-Fenton reactions, where $\mathrm{rGO}, \mathrm{PB}$, and PPy functioned as the skeleton, the active site, and the cross-linker, respectively. As illustrated in Fig. 10a, the pyrrole monomer was oxidized and polymerized on the surface of GO nanosheets during the synthetic process. The obtained PPy wrapped the surface of GO nanosheets and adhered the adjacent GO layers by the $\pi-\pi$ interaction and hydrogen bond interaction, promoting the self-assembly of 2D GO nanosheets to aerogels. In addition, some oxygenated groups on the GO surface were reduced by the reductive pyrrole monomer. The structural impact brought by the cross-linker is shown in Fig. 10b. The rGO/ $\mathrm{PB} / \mathrm{PPy}$ aerogel presented a 3D framework with a myriad of interconnected holes, and the plane size of its rGO skeleton could reach hundreds of microns. The red arrows marked the PPy in the shape of cauliflowers, which acted as the crosslinker inside. The specific surface area and the pore size distribution reckoned by BET measurements were $70 \mathrm{~m}^{2} / \mathrm{g}$ and $5.0-50 \mathrm{~nm}$, respectively. Such a large surface area and mesoporous channels promoted the adsorption and diffusion of pollutants, improving the degradation efficiency. Under the optimal conditions of photo-Fenton reactions with visible light irradiation, the $\mathrm{RhB}$ degradation rate in $30 \mathrm{~min}$ with 
Fig. 9 a Cycle test for the solardriven degradation of methyl orange $(75 \mathrm{~mL} \mathrm{MO}, 10 \mathrm{mg} / \mathrm{L})$ under different reaction systems (1.2 $\mathrm{mL} \mathrm{H}_{2} \mathrm{O}_{2}$ (30 wt\%), initial pH was 3.5); b absorption spectra of the $\mathrm{MO}$ filter liquor photodegraded by the $\mathrm{Fe}_{2} \mathrm{O}_{3}$ powders and $\mathrm{Fe}_{2} \mathrm{O}_{3} / \mathrm{GAs}$ in the presence of 1,10-phenanthroline monohydrate (initial $\mathrm{pH}$ was 3.5); c solar-driven degradation of $\mathrm{MO}$ on $\mathrm{Fe}_{2} \mathrm{O}_{3} / \mathrm{GAs}(1.2 \mathrm{~mL}$ $\mathrm{H}_{2} \mathrm{O}_{2}(30 \mathrm{wt} \%$ ), the initial $\mathrm{pH}$ was adjusted from 3.5 to 9.0 by adding $0.1 \mathrm{~mol} / \mathrm{L} \mathrm{HCl}$ ); d cycle test for the solar-driven degradation of $\mathrm{MO}$ on different catalysts with the initial $\mathrm{pH}$ of 7.0; and e photo-Fenton reaction model of $\mathrm{Fe}_{2} \mathrm{O}_{3} / \mathrm{GAs}$ in the system containing dye pollutants and $\mathrm{H}_{2} \mathrm{O}_{2}$. Reproduced with permission from Ref. [21]. Copyright 2015 The Royal Society of Chemistry

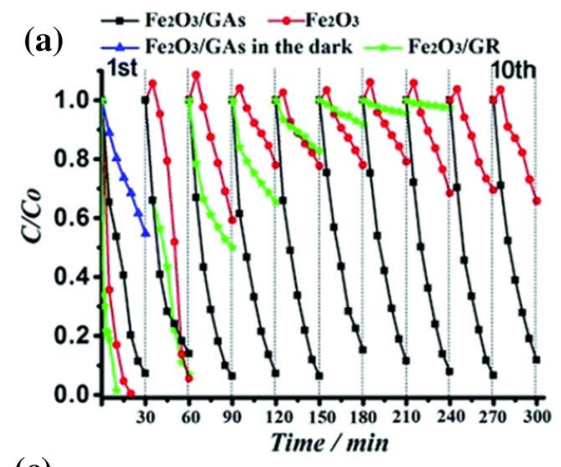

(c)
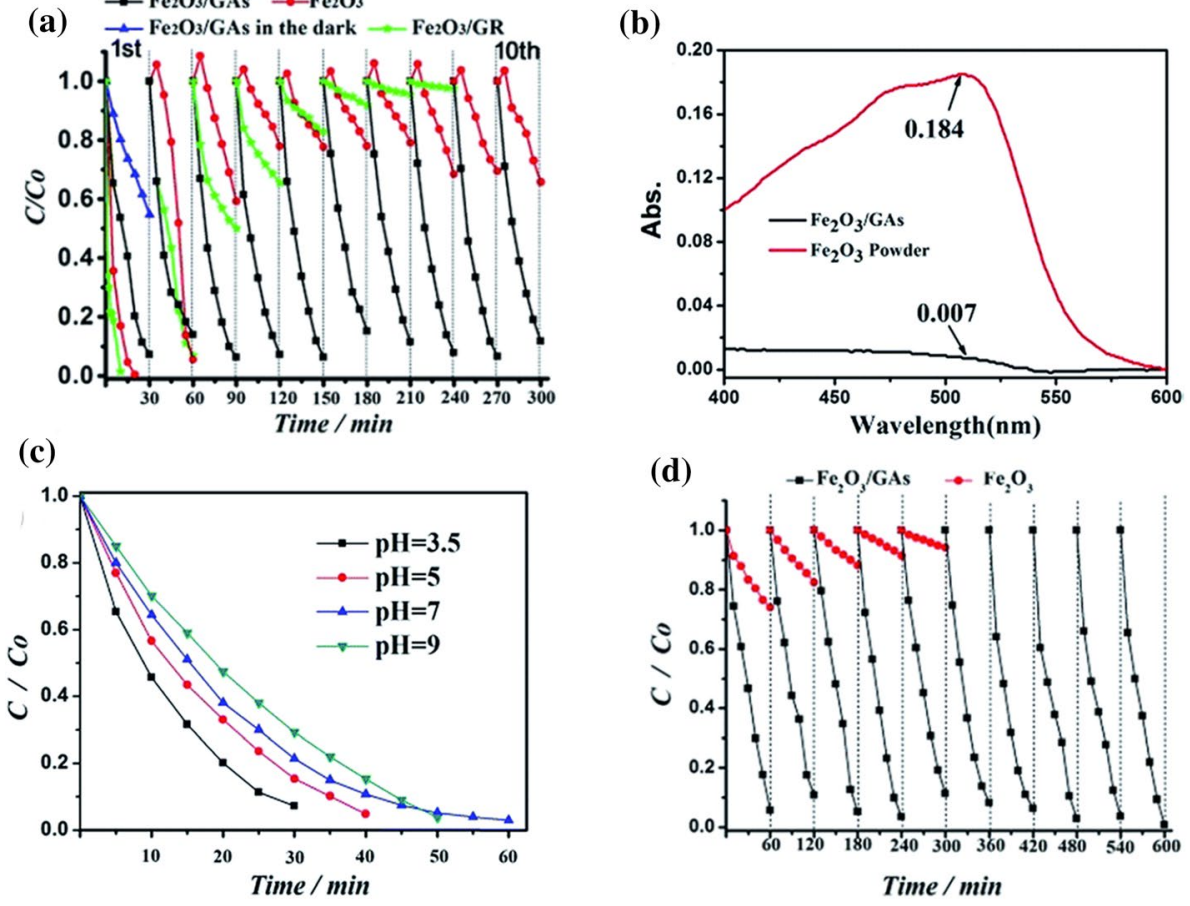

(e)

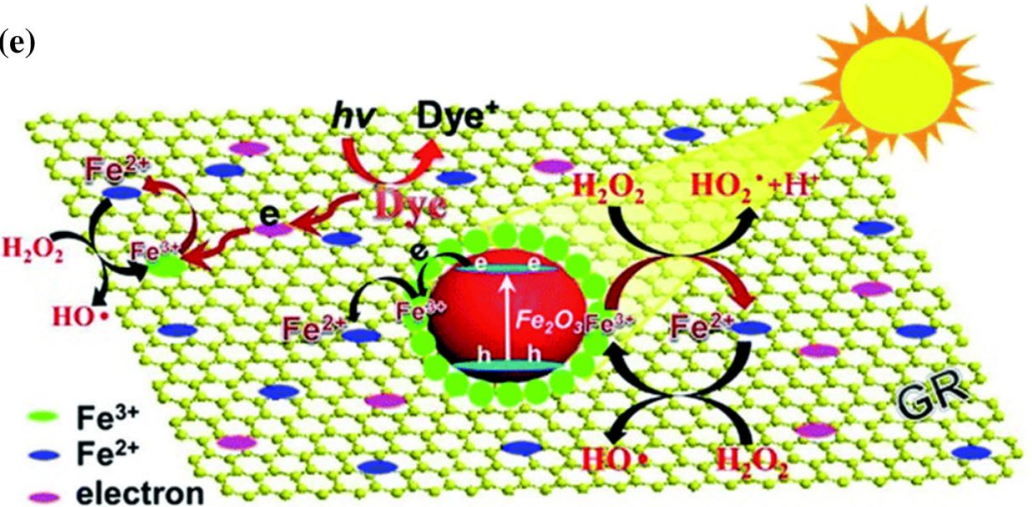

the addition of rGO/PB/PPy was $95.2 \%$, and the calculated pseudo-first-order rate constant was $0.0766 \mathrm{~min}^{-1}$, which were greatly larger than those $\left(5.5 \%\right.$ and $0.00337 \mathrm{~min}^{-1}$, respectively) with $\mathrm{PB}$ nanoparticles. This great improvement can be ascribed to the fact that rGO and PPy are highly capable of adsorbing organic dyes, resulting in a high concentration of RhB near PB nanoparticles. The other reason lays on the outstanding electrical conductivity of $\mathrm{rGO}$ and PPy, which accelerated $\mathrm{Fe}^{3+} / \mathrm{Fe}^{2+}$ circulation.

Other carbon materials further improve graphene aerogels-based photo-Fenton systems by providing additional channels and averting the agglomeration or dissolution of the active sites. Yao et al. [54] employed a two-step synthesis method to sandwich $\mathrm{Fe}_{x} \mathrm{O}_{y}$ between the reduced GO nanosheet (rGS) and the nitrogen-doped carbon layer (NCL) to prepare the $\mathrm{rGS} / \mathrm{Fe}_{x} \mathrm{O}_{y} / \mathrm{NCL}$ composite. As shown in Fig. 10c, thin folds with blue marks indicate the rGSs, and the irregular bulges pointed by red arrows represent NCLs.
rGSs were interconnected to form a consecutive framework because of the adhesion brought by the insertion of NCLs. In a study on the photo-Fenton activity of $\mathrm{rGS} / \mathrm{Fe}_{x} \mathrm{O}_{y} / \mathrm{NCL}$ aerogels, RhB completely disappeared within $150 \mathrm{~min}$. According to the pseudo-first-order equation, the calculated rate constant $K$ was $0.0237 \mathrm{~min}^{-1}$. A TOC removal experiment indicated a mineralization efficiency of $76.1 \%$ in $150 \mathrm{~min}$. Coupled with the high degradation rate maintained in the $\mathrm{pH}$ range of 2.1-10.1, the overall excellent photo-Fenton catalytic performance of the $\mathrm{rGS} / \mathrm{Fe}_{x} \mathrm{O}_{y} / \mathrm{NCL}$ aerogel was exemplified. To disclose the reason, $\mathrm{rGS} / \mathrm{Fe}_{x} \mathrm{O}_{y}$ aerogel was taken as the control group. The degradation rate obtained under the same conditions (66.7\%) was lower than that with the $\mathrm{rGS} / \mathrm{Fe}_{x} \mathrm{O}_{y} / \mathrm{NCL}$ aerogel, which was credited to the $\pi-\pi$ interaction and the formation of hydrogen bonds. Moreover, the superior conductivity of rGSs and NCLs accelerated the electron transfer between $\mathrm{Fe}^{3+}$ and $\mathrm{Fe}^{2+}$, which was supported by the increased reduction current in 
Fig. 10 a Preparation and $\mathbf{b}$ SEM image of rGO/PB/PPy aerogel. Reproduced with permission from Ref. [53]. Copyright 2019 Elsevier B.V. c SEM image of $\mathrm{rGS} / \mathrm{Fe}_{x} \mathrm{O}_{y} /$ NCL aerogel; $\mathbf{d}$ cyclic voltammetry (CV) scans of rGS/Fe $\mathrm{O}_{y} /$ $\mathrm{NCL}$ aerogel and $\boldsymbol{\gamma}-\mathrm{Fe}_{2} \mathrm{O}_{3} \mathrm{NPs}$. Reproduced with permission from Ref. [54]. Copyright 2018 Elsevier B.V. (a)
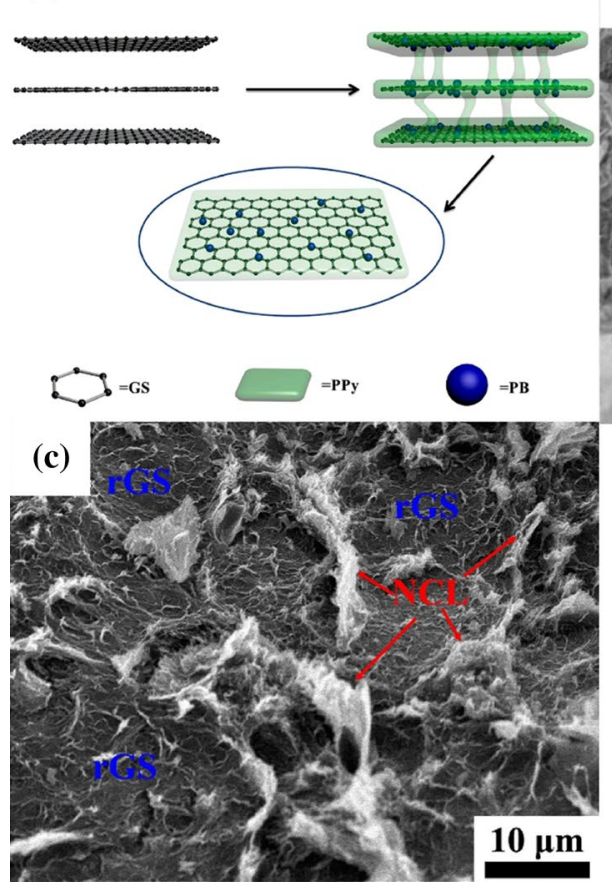

(b)
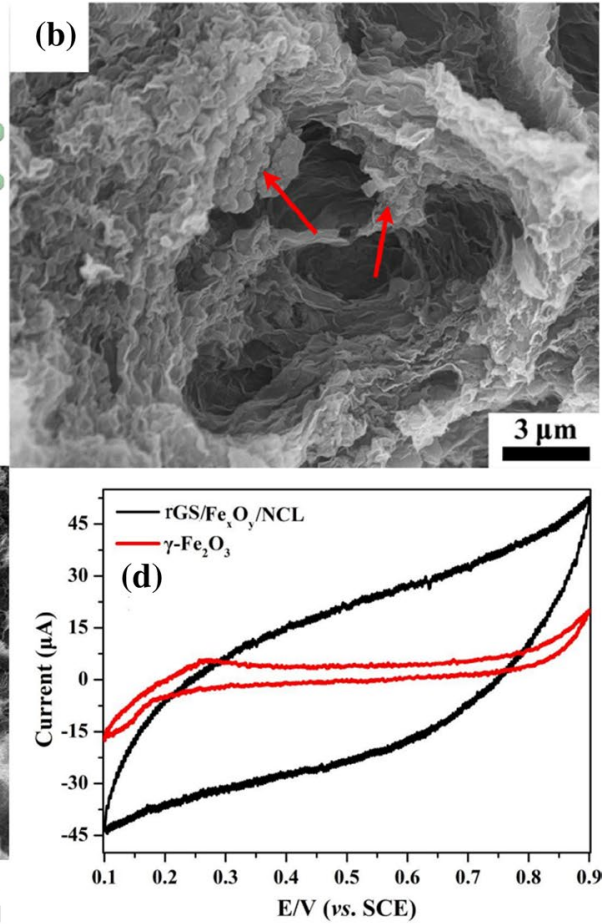

Fig. 10d. Importantly, the degradation rate of RhB with rGS/ $\mathrm{Fe}_{x} \mathrm{O}_{y} / \mathrm{NCL}$ aerogels remained $94.6 \%$ after five cycles. No aggregation or loss of $\mathrm{Fe}_{x} \mathrm{O}_{y}$ was found in the TEM images of the recovered sample. ICP atomic spectroscopy also proved that only $3.3 \mathrm{wt} \%$ of iron was dissolved after the five cycles, indicating the protective effect of NCLs and rGSs on $\mathrm{Fe}_{x} \mathrm{O}_{y}$ nanoparticles. In general, this sandwich structure not only provided multiple channels for the rapid diffusion and adsorption of reactants but also averted the leaching of $\mathrm{Fe}_{x} \mathrm{O}_{y}$, thus achieving the preeminent catalytic ability, stability, and reusability of the structure. A comparison of catalytic performances between non-graphene catalysts and 3D graphene-based catalysts is provided in Table 2 to highlight the significance of the 3D graphene in photo-Fenton reaction.

\section{Three-Dimensional Graphene-Based Hydrogels}

Composed of a porous framework, hydrogels are popular soft materials in electrochemistry, catalysis, sensors, drug delivery, and water treatment [55]. Different from hydrophobic aerogels, hydrogels can absorb large volumes of water in the expanded state because of the abundant hydrophilic groups on their polymeric networks. This extraordinary water-absorbing capability directly results in the adsorptive ability to remove or recycle organic pollutants and heavy metals from aqueous systems, which are not only adsorbed on the surface but also trapped in the inflated 3D framework [56]. Hitherto, many studies have unraveled that graphene-based hydrogels are free from the disadvantages of traditional hydrogels in mechanical properties and adept at the adsorption of organic pollutants. However, few researchers adopted graphene hydrogels in photo-Fenton reactions to degrade the adsorbed pollutants completely $[57,58]$. To our knowledge, Dong et al. [57] reported the only study on the use of graphene-based hydrogels in photo-Fenton systems, demonstrating the feasibility of this direction.

In that report, $\mathrm{Fe}_{3} \mathrm{O}_{4}, \mathrm{rGO}$, and polyacrylamide (PAM) were employed to prepare $\mathrm{Fe}_{3} \mathrm{O}_{4} / \mathrm{rGO} / \mathrm{PAM}$ hydrogels by using a two-step chemical synthesis method. The results of a series of experiments proved that this 3D graphenebased hydrogel has excellent mechanical strength, photoFenton activity, stability, and potential for practical applications. The SEM image of the $\mathrm{Fe}_{3} \mathrm{O}_{4} / \mathrm{rGO} / \mathrm{PAM}$ hydrogel is shown in Fig. 11a. $\mathrm{Fe}_{3} \mathrm{O}_{4}$ nanoparticles were evenly distributed on the surface where PAM chains were wrapped by rGO, forming many small protuberances. The $\mathrm{Fe}_{3} \mathrm{O}_{4} /$ rGO/PAM hydrogel possessed novel mechanical strength. As shown in the compress stress $(\sigma)$-compress strain $(\varepsilon)$ plot (Fig. 11b), the $\mathrm{Fe}_{3} \mathrm{O}_{4} / \mathrm{rGO} / \mathrm{PAM}$ hydrogel had higher compress strain than the PAM hydrogel, suggesting the greater anti-compression property of the former than that of the latter. The excellent tensile property of the $\mathrm{Fe}_{3} \mathrm{O}_{4} /$ rGO/PAM hydrogel is displayed in Fig. 11c. Unlike the fragile PAM hydrogel, the $\mathrm{Fe}_{3} \mathrm{O}_{4} / \mathrm{rGO} / \mathrm{PAM}$ hydrogel was not damaged after the tensile experiment, suggesting its great mechanical strength. In the photo-Fenton reactions, the degradation rate of $\mathrm{RhB}$ with the $\mathrm{Fe}_{3} \mathrm{O}_{4} / \mathrm{rGO} /$ PAM hydrogel reached $90 \%$ under the optimal conditions within $60 \mathrm{~min}$. The high degradation rate was maintained 
Table 2 Recent studies on 3D graphene aerogel-based photo-Fenton systems

\begin{tabular}{|c|c|c|c|c|c|c|c|c|}
\hline Catalyst & Light source & ${ }^{C} \mathrm{H}_{2} \mathrm{O}_{2}$ & $C_{\text {catalyst }}$ & $\mathrm{pH}$ & Pollutant & Efficiency & $\begin{array}{l}\text { Efficiency with- } \\
\text { out graphene }\end{array}$ & References \\
\hline $\mathrm{Fe}_{2} \mathrm{O}_{3} / \mathrm{GAs}$ & $\begin{array}{l}300 \mathrm{~W} \text { Xe lamp, } \\
\text { AM } 1.5\end{array}$ & $16 \mathrm{~mL} / \mathrm{L}$ & - & 3.5 & $\begin{array}{c}\mathrm{MO}(75 \mathrm{~mL} \\
10 \mathrm{mg} / \mathrm{L})\end{array}$ & $\begin{array}{l}\sim 93 \% \text { in } 30 \mathrm{~min} \\
\text { in the } 4 \text { th cycle }\end{array}$ & $\begin{array}{l}\sim 22 \% \text { in } 30 \mathrm{~min} \\
\text { in the } 4 \text { th cycle }\end{array}$ & {$[21]$} \\
\hline $\mathrm{CoFe}_{2} \mathrm{O}_{4} / \mathrm{GAs}$ & $\begin{array}{l}300 \mathrm{~W} \text { Xe lamp, } \\
\text { AM } 1.5\end{array}$ & $150 \mathrm{mmol} / \mathrm{L}$ & - & 3.5 & $\begin{array}{c}\text { MO (75 mL, } \\
10 \mathrm{mg} / \mathrm{L})\end{array}$ & $\begin{array}{l}\sim 100 \% \text { in } \\
30 \text { min in the } \\
5 \text { th cycle }\end{array}$ & $\begin{array}{l}\sim 40 \% \text { in } 30 \mathrm{~min} \\
\text { in the } 5 \text { th cycle }\end{array}$ & {$[52]$} \\
\hline $\begin{array}{l}\text { GO-carbon } \\
\text { nanotubes } \\
-\alpha-\mathrm{FeOOH} \\
\text { aerogel }\end{array}$ & $\begin{array}{r}125 \mathrm{~W} \text { mercury } \\
\text { lamp, } 365 \mathrm{~nm}\end{array}$ & $0.55 \mathrm{mmol} / \mathrm{L}$ & $125 \mathrm{mg} / \mathrm{L}$ & $3.18-9$ & $\begin{array}{l}\text { Orange II } \\
(400 \mathrm{~mL}, \\
40 \mathrm{mg} / \mathrm{L})\end{array}$ & $\sim 99 \%$ in $60 \mathrm{~min}$ & $60.7 \%$ in $60 \mathrm{~min}$ & {$[51]$} \\
\hline $\begin{array}{c}\mathrm{Nano}-\mathrm{FeO}(\mathrm{OH}) / \\
\text { rGO aerogel }\end{array}$ & $\begin{array}{l}500 \mathrm{~W} \text { Xe } \\
\text { lamp, > } 420 \mathrm{~nm}\end{array}$ & $20 \mathrm{mmol} / \mathrm{L}$ & - & 3.00 & $\begin{array}{l}\text { 4-chlorophe- } \\
\text { nol (50 mL, } \\
10 \mathrm{mg} / \mathrm{L})\end{array}$ & $100 \%$ in $80 \mathrm{~min}$ & - & {$[38]$} \\
\hline $\begin{array}{c}\mathrm{Fe}_{2} \mathrm{O}_{3} / \mathrm{rGO} \\
\text { aerogel }\end{array}$ & $\begin{array}{l}300 \mathrm{~W} \text { Xe } \\
\text { lamp, > } 400 \mathrm{~nm}\end{array}$ & $16.67 \mathrm{~mL} / \mathrm{L}$ & $83.33 \mathrm{mg} / \mathrm{L}$ & 6.5 & $\begin{array}{c}\mathrm{RhB}(60 \mathrm{~mL}, \\
15 \mathrm{mg} / \mathrm{L})\end{array}$ & $100 \%$ in $120 \mathrm{~min}$ & $\begin{array}{l}\sim 40 \% \text { in } \\
120 \text { min }\end{array}$ & {$[65]$} \\
\hline $\begin{array}{l}\text { rGO/Prussian } \\
\text { blue/polypyr- } \\
\text { role aerogel }\end{array}$ & $\begin{array}{l}300 \mathrm{~W} \text { Xe } \\
\text { lamp, > } 420 \mathrm{~nm}\end{array}$ & $2 \mathrm{~mL} / \mathrm{L}$ & $0.2 \mathrm{~g} / \mathrm{L}$ & 6.18 & $\begin{array}{l}\mathrm{RhB}(50 \mathrm{~mL}, \\
10 \mathrm{mg} / \mathrm{L})\end{array}$ & $95.2 \%$ in $30 \mathrm{~min}$ & $5.5 \%$ in $30 \mathrm{~min}$ & {$[53]$} \\
\hline $\begin{array}{c}\text { rGO nanosheet/ } \\
\mathrm{Fe}_{x} \mathrm{O}_{y} / \text { nitrogen- } \\
\text { doped carbon } \\
\text { layer aerogel }\end{array}$ & $\begin{array}{l}\mathrm{Xe} \\
\quad \text { lamp, > } 420 \mathrm{~nm}\end{array}$ & $16.67 \mathrm{~mL} / \mathrm{L}$ & $0.5 \mathrm{~g} / \mathrm{L}$ & 6.5 & $\begin{array}{l}\mathrm{RhB}(60 \mathrm{~mL}, \\
10 \mathrm{mg} / \mathrm{L})\end{array}$ & $\begin{array}{l}>99.0 \% \text { in } \\
150 \mathrm{~min}\end{array}$ & $\begin{array}{l}\sim 32 \% \text { in } \\
\quad 150 \mathrm{~min}\end{array}$ & {$[54]$} \\
\hline
\end{tabular}

Fig. 11 a SEM image of $0.2 \mathrm{Fe} / \mathrm{RGO} / \mathrm{PAM}$ hydrogel; $\mathbf{b}$ compress stress $(\sigma)$-compress strain $(\varepsilon)$ plot of PAM hydrogel and $0.2 \mathrm{Fe} / \mathrm{GO} / \mathrm{PAM}$ hydrogel; c stretchable tests of PAM hydrogel and $0.2 \mathrm{Fe} / \mathrm{RGO} / \mathrm{PAM}$ hydrogel; and d photo-Fentonreaction for the degradation of fine chemical wastewater over $0.2 \mathrm{Fe} / \mathrm{RGO} / \mathrm{PAM}$ (benzenoid wastewater, $\mathrm{pH}=4.5$, visible light: $\lambda>420 \mathrm{~nm}$ ). Reproduced with permission from Ref. [57]. Copyright 2017 Elsevier B.V.
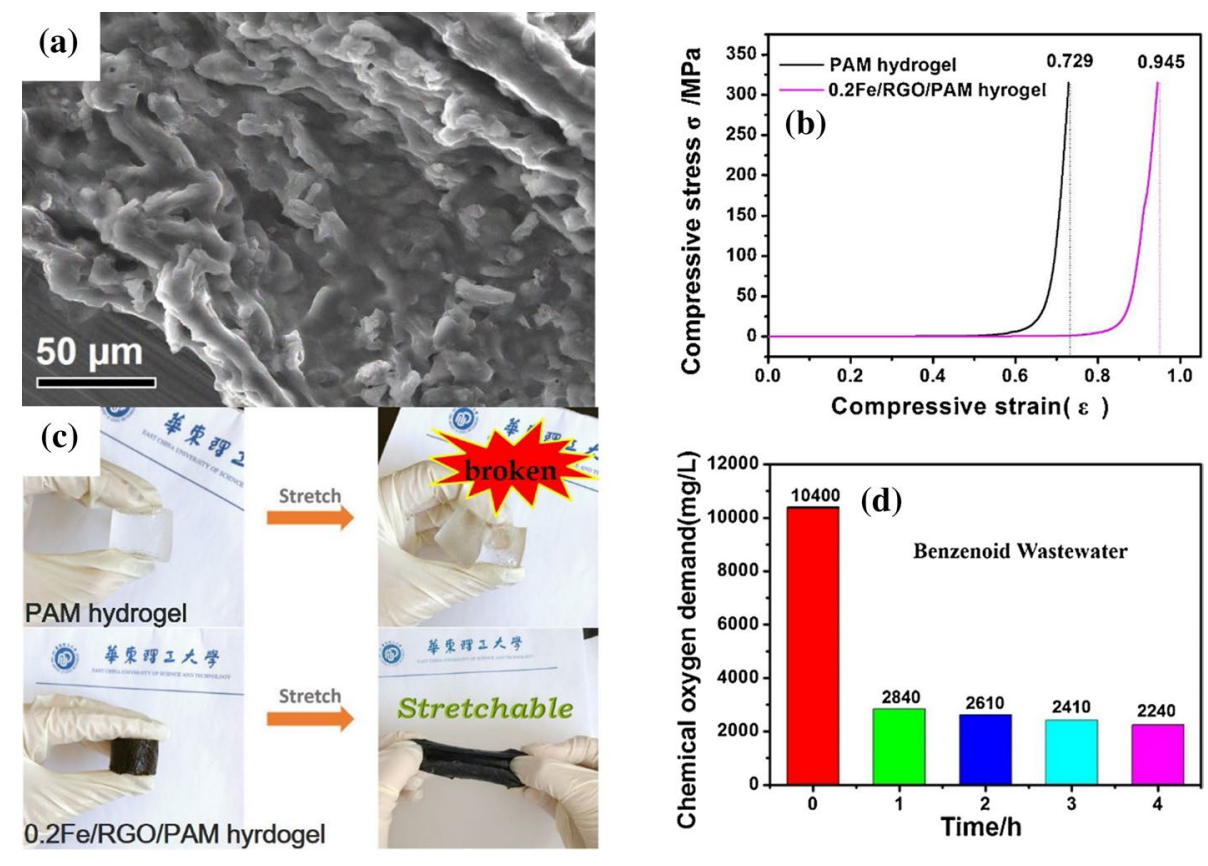

in the $\mathrm{pH}$ range of 3.5-6.5, suggesting that the $\mathrm{Fe}_{3} \mathrm{O}_{4} /$ rGO/PAM hydrogel is an excellent photo-Fenton catalyst under multiple conditions. Meanwhile, the catalytic stability was ascertained by over $90 \%$ removal of RhB after 10 cycles. The concentration of $\mathrm{Fe}^{2+}$ in aqueous solutions of the ground and unground $\mathrm{Fe}_{3} \mathrm{O}_{4} / \mathrm{rGO} / \mathrm{PAM}$ hydrogels was measured using Phen as the chromogenic agent to investigate the stability of the hydrogels. The intensity of the peak ascribed to the ground $\mathrm{Fe}_{3} \mathrm{O}_{4} / \mathrm{rGO} / \mathrm{PAM}$ hydrogel (1.357) was much higher than that of the unground one (0.298), which manifested that the hybrid hydrogel greatly retarded the iron leaching and deactivation of catalysts. Original fine chemical wastewater was also chosen as the model of actual water pollution to test the practical application potential of the $\mathrm{Fe}_{3} \mathrm{O}_{4} / \mathrm{rGO} / \mathrm{PAM}$ hydrogel (Fig. 11d). The initial chemical oxygen demand (COD) of 
the sewage was $10,400 \mathrm{mg} / \mathrm{L}$, and it dropped to $2840 \mathrm{mg} / \mathrm{L}$ after $1 \mathrm{~h}$ of visible light irradiation, proving the potential for actual wastewater treatment.

Compared with the 2D graphene-based materials, the novel 3D graphene-based materials are equipped with more practical advantages. Graphene-based aerogels are characterized by low density and high mechanical strength, and the super adsorption capacity of hydrogels is also alluring. The enhanced adsorption and diffusion of pollutants brought by internal multi-channels, the inhibitory effect on agglomeration or dissolution of active sites, and the convenience for recycling as 3D macroscopic catalysts endow 3D graphene-based materials with great value in practical application. Thus, researchers tend to focus on the stability of the material and the trial for degrading actual sewage to lay a solid foundation for the possible application in industrial wastewater treatment in the future. In general, many problems remain to be solved before the practical application of 3D graphene-based materials, including but not limited to the high cost of synthesis and difficulties in catalyst regeneration. Nevertheless, 3D graphene-based materials are the general directions of future graphene-based systems, at least in the photo-Fenton degradation of pollutants.

\section{Conclusions and Outlooks}

In this study, the advances of graphene-based photo-Fenton systems were briefly introduced according to the classification of 2D and 3D graphene-based catalysts and discussed in terms of their special morphologic structures, great enhancements brought by graphene, the efficiency of treating pollutants, and practical application potential. Iron compounds have been selected as the active sites and anchored to the surface of graphene in 2D graphene-based photo-Fenton systems to mitigate the inevitable iron leaching in traditional photo-Fenton reactions. The consequent heterogeneous catalysis hampers the loss of catalytic activity and secondary pollution caused by iron sludge. The excellent light absorption, pollutant adsorption, and electron mobility of graphene materials are on full display in 2D graphene-based photo-Fenton systems. $\mathrm{Fe}^{3+}$ reduction and $\mathrm{Fe}^{3+} / \mathrm{Fe}^{2+}$ circulation can be carried out efficiently through rapid electron transfer among various active components, thus achieving alluring performance in the degradation of organic pollutants. In addition, many magnetic materials, such as $\mathrm{Fe}_{3} \mathrm{O}_{4}$ and $\mathrm{ZnFe}_{2} \mathrm{O}_{4}$, which can be quickly separated from aqueous solutions by an external magnetic field, were employed to prepare 2D graphene-based magnetically separable catalysts to overcome the difficulty in $2 \mathrm{D}$ catalyst recovery to some extent.

Three-dimensional graphene-based materials, including graphene aerogels and graphene hydrogels, inherit the aforementioned advantages of 2D graphene-based materials and are equipped with additional porous 3D macroscopic structures. The structures not only provide a large number of internal channels for the diffusion and aggregation of pollutants and $\mathrm{H}_{2} \mathrm{O}_{2}$ but also effectively encapsulate the active sites, preventing their agglomeration or dissolution to form iron sludge. Such 3D macroscopic structures render the convenience in recycling. In addition, aerogels and hydrogels are characterized by their own properties. The former has extremely low density and high mechanical strength, whereas the latter possesses an excellent adsorption capacity for organic pollutants and heavy metals in aqueous solution. In general, 3D graphene-based composite catalysts are the future directions of graphene-based photo-Fenton systems.

Loading active components on $2 \mathrm{D} / 3 \mathrm{D}$ graphene is challenging, considering its large surface that is prone to fold. In addition, the traditional synthetic method of GO is complex and not eco-friendly. Thus, researchers should still pursue the synthesis of highly active graphene-based composites with stably and evenly loaded active substances by using simple, low-cost, and eco-friendly methods. Moreover, 3D graphene-based materials do not necessarily have to be in the form of aerogels or hydrogels because both forms lack robustness and are costly in synthesis and reactivation. For example, recent studies have used sponge as a cheap and robust support of graphene-based Fenton catalysts for the treatment of actual wastewater. The synthesis was simpler and cheaper than traditional methods. It provided excellent inspiration for the future preparation of 3D graphene-based materials. In sum, graphene materials still have promising application potential in photo-Fenton reactions and industrial water treatment.

Open Access This article is licensed under a Creative Commons Attribution 4.0 International License, which permits use, sharing, adaptation, distribution and reproduction in any medium or format, as long as you give appropriate credit to the original author(s) and the source, provide a link to the Creative Commons licence, and indicate if changes were made. The images or other third party material in this article are included in the article's Creative Commons licence, unless indicated otherwise in a credit line to the material. If material is not included in the article's Creative Commons licence and your intended use is not permitted by statutory regulation or exceeds the permitted use, you will need to obtain permission directly from the copyright holder. To view a copy of this licence, visit http://creativecommons.org/licenses/by/4.0/.

\section{References}

1. Clarizia L, Russo D, Di Somma I et al (2017) Homogeneous photo-Fenton processes at near neutral pH: a review. Appl Catal B Environ 209:358-371

2. Giannakis $S$ (2019) A review of the concepts, recent advances and niche applications of the (photo) Fenton process, beyond water/wastewater treatment: surface functionalization, biomass 
treatment, combatting cancer and other medical uses. Appl Catal B Environ 248:309-319

3. Chen YB, Li JF, Liao PY et al (2020) Cascaded electron transition in $\mathrm{CuWO}_{4} / \mathrm{CdS} / \mathrm{CDs}$ heterostructure accelerating charge separation towards enhanced photocatalytic activity. Chin Chem Lett 31(6):1516-1519

4. Du MM, Yi QY, Ji JH et al (2020) Sustainable activation of peroxymonosulfate by the $\mathrm{Mo}(\mathrm{IV})$ in $\mathrm{MoS}_{2}$ for the remediation of aromatic organic pollutants. Chin Chem Lett 31(10):2803-2808

5. Dong CC, Ji JH, Yang Z et al (2019) Research progress of photocatalysis based on highly dispersed titanium in mesoporous $\mathrm{SiO}_{2}$. Chin Chem Lett 30(4):853-862

6. Nie CY, Dai ZH, Liu WJ et al (2020) Criteria of active sites in nonradical persulfate activation process from integrated experimental and theoretical investigations: boron-nitrogen-co-doped nanocarbon-mediated peroxydisulfate activation as an example. Environ Sci Nano 7(7):1899-1911

7. Zou JP, Chen Y, Liu SS et al (2019) Electrochemical oxidation and advanced oxidation processes using a 3D hexagonal $\mathrm{Co}_{3} \mathrm{O}_{4}$ array anode for 4-nitrophenol decomposition coupled with simultaneous $\mathrm{CO}_{2}$ conversion to liquid fuels via a flowerlike $\mathrm{CuO}$ cathode. Water Res 150:330-339

8. Zhu M, Zhang LS, Liu SS et al (2020) Degradation of 4-nitrophenol by electrocatalysis and advanced oxidation processes using $\mathrm{Co}_{3} \mathrm{O}_{4} @ \mathrm{C}$ anode coupled with simultaneous $\mathrm{CO}_{2}$ reduction via $\mathrm{SnO}_{2} / \mathrm{CC}$ cathode. Chin Chem Lett 31(7):1961-1965

9. Nie CY, Dai ZH, Meng $\mathrm{H}$ et al (2019) Peroxydisulfate activation by positively polarized carbocatalyst for enhanced removal of aqueous organic pollutants. Water Res 166:115043

10. Duan XG, Ao ZM, Zhang HY et al (2018) Nanodiamonds in $\mathrm{sp}^{2} /$ $\mathrm{sp}^{3}$ configuration for radical to nonradical oxidation: core-shell layer dependence. Appl Catal B Environ 222:176-181

11. Zhang MH, Dong H, Zhao L et al (2019) A review on Fenton process for organic wastewater treatment based on optimization perspective. Sci Total Environ 670:110-121

12. Zhu YP, Zhu RL, Xi YF et al (2019) Strategies for enhancing the heterogeneous Fenton catalytic reactivity: a review. Appl Catal B Environ 255:117739

13. Bokare AD, Choi W (2014) Review of iron-free Fenton-like systems for activating $\mathrm{H}_{2} \mathrm{O}_{2}$ in advanced oxidation processes. $\mathrm{J}$ Hazard Mater 275:121-135

14. Babuponnusami A, Muthukumar K (2014) A review on Fenton and improvements to the Fenton process for wastewater treatment. J Environ Chem Eng 2(1):557-572

15. Shen B, Dong CC, Ji JH et al (2019) Efficient Fe(III)/Fe(II) cycling triggered by $\mathrm{MoO}_{2}$ in Fenton reaction for the degradation of dye molecules and the reduction of $\mathrm{Cr}(\mathrm{VI})$. Chin Chem Lett 30(12):2205-2210

16. Wang C, Liu YB, Zhou T et al (2019) Efficient decomposition of sulfamethoxazole in a novel neutral Fered-Fenton like/oxalate system based on effective heterogeneous-homogeneous iron cycle. Chin Chem Lett 30(12):2231-2235

17. Jiang ZY, Wang LZ, Lei JY et al (2019) Photo-Fenton degradation of phenol by $\mathrm{CdS} / \mathrm{rGO} / \mathrm{Fe}^{2+}$ at natural $\mathrm{pH}$ with in situgenerated $\mathrm{H}_{2} \mathrm{O}_{2}$. Appl Catal B Environ 241:367-374

18. Vorontsov AV (2019) Advancing Fenton and photo-Fenton water treatment through the catalyst design. J Hazard Mater 372:103-112

19. He J, Yang XF, Men B et al (2014) Heterogeneous Fenton oxidation of catechol and 4-chlorocatechol catalyzed by nano- $\mathrm{Fe}_{3} \mathrm{O}_{4}$ : role of the interface. Chem Eng J 258:433-441

20. Qiu BC, Li QY, Shen B et al (2016) Stöber-like method to synthesize ultradispersed $\mathrm{Fe}_{3} \mathrm{O}_{4}$ nanoparticles on graphene with excellent Photo-Fenton reaction and high-performance lithium storage. Appl Catal B Environ 183:216-223

21. Qiu BC, Xing MY, Zhang JL (2015) Stöber-like method to synthesize ultralight, porous, stretchable $\mathrm{Fe}_{2} \mathrm{O}_{3}$ /graphene aerogels for excellent performance in photo-Fenton reaction and electrochemical capacitors. J Mater Chem A 3(24):12820-12827

22. Chowdhury S, Balasubramanian R (2014) Graphene/semiconductor nanocomposites (GSNs) for heterogeneous photocatalytic decolorization of wastewaters contaminated with synthetic dyes: a review. Appl Catal B Environ 160:307-324

23. Pan XR, Ji JH, Zhang NN et al (2020) Research progress of graphene-based nanomaterials for the environmental remediation. Chin Chem Lett 31(6):1462-1473

24. Nidheesh PV (2017) Graphene-based materials supported advanced oxidation processes for water and wastewater treatment: a review. Environ Sci Pollut Res 24(35):27047-27069

25. Fu YS, Wang X (2011) Magnetically separable $\mathrm{ZnFe}_{2} \mathrm{O}_{4}$-graphene catalyst and its high photocatalytic performance under visible light irradiation. Ind Eng Chem Res 50(12):7210-7218

26. Park CM, Kim YM, Kim KH et al (2019) Potential utility of graphene-based nano spinel ferrites as adsorbent and photocatalyst for removing organic/inorganic contaminants from aqueous solutions: a mini review. Chemosphere 221:392-402

27. Ojha DP, Joshi MK, Kim HJ (2017) Photo-Fenton degradation of organic pollutants using a zinc oxide decorated iron oxide/reduced graphene oxide nanocomposite. Ceram Int 43(1):1290-1297

28. Liang HJ, Hua P, Zhou YF et al (2019) Fabrication of $\mathrm{Cu} / \mathrm{rGO} /$ $\mathrm{MoS}_{2}$ nanohybrid with energetic visible-light response for degradation of rhodamine B. Chin Chem Lett 30(12):2245-2248

29. Phiri J, Johansson LS, Gane P et al (2018) A comparative study of mechanical, thermal and electrical properties of graphene-, graphene oxide- and reduced graphene oxide-doped microfibrillated cellulose nanocomposites. Compos Part B Eng 147:104-113

30. Liu J, Fang WZ, Wang YH et al (2018) Gold-loaded graphene oxide/PDPB composites for the synchronous removal of $\mathrm{Cr}(\mathrm{VI})$ and phenol. Chin J Catal 39(1):8-15

31. Liu YY, Jin W, Zhao YP et al (2017) Enhanced catalytic degradation of methylene blue by $\alpha-\mathrm{Fe}_{2} \mathrm{O}_{3} /$ graphene oxide via heterogeneous photo-Fenton reactions. Appl Catal B Environ 206:642-652

32. Liu B, Tian LH, Wang R et al (2017) Pyrrolic-N-doped graphene oxide $/ \mathrm{Fe}_{2} \mathrm{O}_{3}$ mesocrystal nanocomposite: efficient charge transfer and enhanced photo-Fenton catalytic activity. Appl Surf Sci 422:607-615

33. Wang PJ, Wang LQ, Sun Q et al (2016) Preparation and performance of $\mathrm{Fe}_{3} \mathrm{O}_{4} @$ hydrophilic graphene composites with excellent photo-Fenton activity for photocatalysis. Mater Lett 183:61-64

34. Yu L, Chen JD, Liang Z et al (2016) Degradation of phenol using $\mathrm{Fe}_{3} \mathrm{O}_{4}-\mathrm{GO}$ nanocomposite as a heterogeneous photo-Fenton catalyst. Sep Purif Technol 171:80-87

35. Su SS, Liu YY, Liu XM et al (2019) Transformation pathway and degradation mechanism of methylene blue through $\beta-\mathrm{FeOOH} @$ GO catalyzed photo-Fenton-like system. Chemosphere 218:83-92

36. He S, Yan C, Chen XZ et al (2020) Construction of core-shell heterojunction regulating $\alpha-\mathrm{Fe}_{2} \mathrm{O}_{3}$ layer on $\mathrm{CeO}_{2}$ nanotube arrays enables highly efficient Z-scheme photoelectrocatalysis. Appl Catal B Environ 119138

37. Guo S, Zhang GK, Guo YD et al (2013) Graphene oxide- $\mathrm{Fe}_{2} \mathrm{O}_{3}$ hybrid material as highly efficient heterogeneous catalyst for degradation of organic contaminants. Carbon 60:437-444

38. Liu RL, Xu YM, Chen BL (2018) Self-assembled nano-FeO(OH)/ reduced graphene oxide aerogel as a reusable catalyst for photoFenton degradation of phenolic organics. Environ Sci Technol 52(12):7043-7053

39. Casbeer E, Sharma VK, Li XZ (2012) Synthesis and photocatalytic activity of ferrites under visible light: a review. Sep Purif Technol 87:1-14

40. Nawaz M, Shahzad A, Tahir K et al (2020) Photo-Fenton reaction for the degradation of sulfamethoxazole using a multi-walled carbon nanotube- $\mathrm{NiFe}_{2} \mathrm{O}_{4}$ composite. Chem Eng J 382:123053

41. Liu SQ, Xiao B, Feng LR et al (2013) Graphene oxide enhances the Fenton-like photocatalytic activity of nickel ferrite for 
degradation of dyes under visible light irradiation. Carbon 64:197-206

42. Zhou Y, Xiao B, Liu SQ et al (2016) Photo-Fenton degradation of ammonia via a manganese-iron double-active component catalyst of graphene-manganese ferrite under visible light. Chem Eng J 283:266-275

43. He HY, Lu J (2017) Highly photocatalytic activities of magnetically separable reduced graphene oxide- $\mathrm{CoFe}_{2} \mathrm{O}_{4}$ hybrid nanostructures in dye photodegradation. Sep Purif Technol 172:374-381

44. Gong QJ, Liu Y, Dang Z (2019) Core-shell structured $\mathrm{Fe}_{3} \mathrm{O}_{4} @$ GO@MIL-100(Fe) magnetic nanoparticles as heterogeneous photo-Fenton catalyst for 2,4-dichlorophenol degradation under visible light. J Hazard Mater 371:677-686

45. Yi QY, Du MM, Shen B et al (2020) Hollow $\mathrm{Fe}_{3} \mathrm{O}_{4} /$ carbon with surface mesopores derived from MOFs for enhanced lithium storage performance. Sci Bull 65(3):233-242

46. Xie A, Cui JY, Yang J et al (2020) Graphene oxide/Fe(III)-based metal-organic framework membrane for enhanced water purification based on synergistic separation and photo-Fenton processes. Appl Catal B Environ 264:118548

47. Liu N, Huang WY, Zhang XD et al (2018) Ultrathin graphene oxide encapsulated in uniform MIL-88A (Fe) for enhanced visible light-driven photodegradation of RhB. Appl Catal B Environ 221:119-128

48. Yang C, You X, Cheng JH et al (2017) A novel visible-lightdriven In-based MOF/graphene oxide composite photocatalyst with enhanced photocatalytic activity toward the degradation of amoxicillin. Appl Catal B Environ 200:673-680

49. Ananthanarayanan A, Wang XW, Routh P et al (2014) Facile synthesis of graphene quantum dots from 3D graphene and their application for $\mathrm{Fe}^{3+}$ sensing. Adv Funct Mater 24(20):3021-3026

50. Cao XH, Shi YM, Shi WH et al (2011) Preparation of novel 3D graphene networks for supercapacitor applications. Small 7(22):3163-3168

51. Liu YY, Liu XM, Zhao YP et al (2017) Aligned $\alpha-\mathrm{FeOOH}$ nanorods anchored on a graphene oxide-carbon nanotubes aerogel can serve as an effective Fenton-like oxidation catalyst. Appl Catal B Environ 213:74-86

52. Qiu BC, Deng YX, Du MM et al (2016) Ultradispersed cobalt ferrite nanoparticles assembled in graphene aerogel for continuous photo-Fenton reaction and enhanced lithium storage performance. Sci Rep 6:29099

53. Tong X, Jia WJ, Li YM et al (2019) One-step preparation of reduced graphene oxide/Prussian blue/polypyrrole aerogel and their enhanced photo-Fenton performance. J Taiwan Inst Chem E 102:92-98

54. Yao TJ, Jia WJ, Feng Y et al (2019) Preparation of reduced graphene oxide nanosheet/ $\mathrm{Fe}_{x} \mathrm{O}_{y} /$ nitrogen-doped carbon layer aerogel as photo-Fenton catalyst with enhanced degradation activity and reusability. J Hazard Mater 362:62-71

55. Lu H, Zhang ST, Guo L et al (2017) Applications of graphene-based composite hydrogels: a review. RSC Adv 7(80):51008-51020

56. Khan M, Lo IMC (2016) A holistic review of hydrogel applications in the adsorptive removal of aqueous pollutants: recent progress, challenges, and perspectives. Water Res 106:259-271

57. Dong CC, Lu J, Qiu BC et al (2018) Developing stretchable and graphene-oxide-based hydrogel for the removal of organic pollutants and metal ions. Appl Catal B Environ 222:146-156

58. Yi QY, Tan JL, Liu WY et al (2020) Peroxymonosulfate activation by three-dimensional cobalt hydroxide/graphene oxide hydrogel for wastewater treatment through an automated process. Chem Eng J 400:125965

59. Shao PH, Tian JY, Liu BR et al (2015) Morphology-tunable ultrafine metal oxide nanostructures uniformly grown on graphene and their applications in the photo-Fenton system. Nanoscale 7(34):14254-14263
60. Yang XL, Chen W, Huang JF et al (2015) Rapid degradation of methylene blue in a novel heterogeneous $\mathrm{Fe}_{3} \mathrm{O}_{4} @ \mathrm{rGO} @ \mathrm{TiO}_{2}$ catalyzed photo-Fenton system. Sci Rep 5:10632

61. Boruah PK, Sharma B, Karbhal I et al (2017) Ammonia-modified graphene sheets decorated with magnetic $\mathrm{Fe}_{3} \mathrm{O}_{4}$ nanoparticles for the photocatalytic and photo-Fenton degradation of phenolic compounds under sunlight irradiation. J Hazard Mater 325:90-100

62. Arshad A, Iqbal J, Ahmad I et al (2018) Graphene/ $/ \mathrm{Fe}_{3} \mathrm{O}_{4}$ nanocomposite: interplay between photo-Fenton type reaction, and carbon purity for the removal of methyl orange. Ceram Int 44(3):2643-2648

63. Wang FF, Yu XL, Ge MF et al (2019) Facile self-assembly synthesis of $\gamma-\mathrm{Fe}_{2} \mathrm{O}_{3}$ /graphene oxide for enhanced photo-Fenton reaction. Environ Pollut 248:229-237

64. Saleh R, Taufik A (2019) Photo-Fenton degradation of methylene blue in the presence of $\mathrm{Au}-\mathrm{Fe}_{3} \mathrm{O}_{4}$ /graphene composites under UV and visible light at near neutral $\mathrm{pH}$ : effect of coexisting inorganic anion. Environ Nanotechnol Monit Manag 11:100221

65. Feng Y, Yao TJ, Yang Y et al (2018) One-step preparation of $\mathrm{Fe}_{2} \mathrm{O}_{3}$ /reduced graphene oxide aerogel as heterogeneous Fentonlike catalyst for enhanced photo-degradation of organic dyes. Chemistryselect 3(31):9062-9070

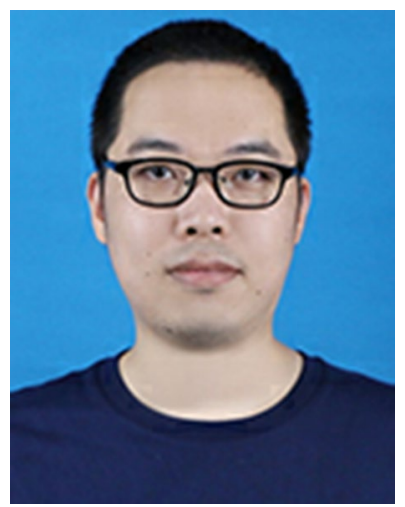

Bocheng Qiu received his bachelor's degree (2012) from Nanjing Agricultural University and $\mathrm{PhD}$ degree (2017) from East China University of Science and Technology. From 2017 to 2020, he was a post-doctoral fellow at the Hong Kong Polytechnic University. He is currently a professor at College of Sciences in Nanjing Agricultural University. His research interest focuses on the design and controlled synthesis of transition-metal-based hybrid materials and their applications in photo-/electrocatalysis

and energy storage.

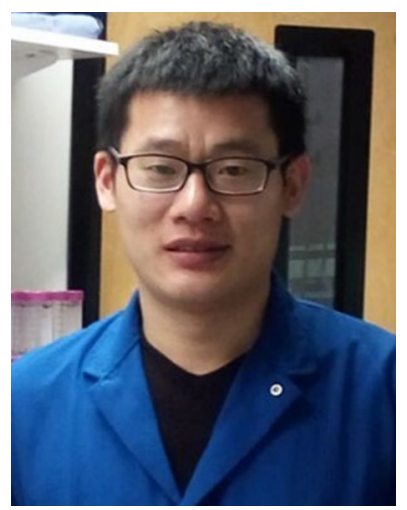

Dr. Mingyang Xing is a professor and supervisor of postgraduate in the School of Chemistry and Molecular Engineering, East China University of Science and Technology (ECUST). He obtained his Doctoral Degree in 2012 from ECUST and then worked in University of California, Riverside, as a visiting scholar for 1 year. His research focuses on the design and preparation of functional nanomaterials and applications to the environmental and energy fields. $\mathrm{He}$ has published more than 90 papers in SCI journals in these areas, which have been cited more than 7200 times (H-index: 48) 